\title{
Spatially Continuous Characterization of Forest Canopy Structure and Subcanopy Irradiance Derived from Handheld Radiometer Surveys ${ }^{\mathscr{O}}$
}

\author{
GiUlia MazzotTi \\ WSL Institute for Snow and Avalanche Research SLF, Davos Dorf, and Laboratory of Hydraulics, Hydrology and \\ Glaciology, ETH Zurich, Zurich, Switzerland \\ JOHANNA MALLE \\ Department of Geography, Northumbria University, Newcastle, United Kingdom, and WSL Institute for Snow and \\ Avalanche Research SLF, Davos Dorf, Switzerland \\ SARAH BARR AND TOBIAS JONAS \\ WSL Institute for Snow and Avalanche Research SLF, Davos Dorf, Switzerland
}

(Manuscript received 3 August 2018, in final form 6 May 2019)

\begin{abstract}
Small-scale variations in radiative transfer through forest canopies are strongly linked to canopy structural heterogeneity. To date, upscaling of radiative transfer parameterizations developed at the point scale is hampered by (i) poor representation of canopy structure variability and (ii) limited spatially explicit subcanopy irradiance data to assess the performance of radiative transfer schemes at typical resolutions of land surface models. This study presents a novel approach for efficient in situ characterization of canopy structure and subcanopy irradiance over large spatial extents. The method involves a handheld radiometer assembly mounted on a motorized gimbal developed for nonstationary continuous measurements of shortwave and longwave radiation along forest transects. In combination with radiation and temperature data from a stationary reference station, spatially resolved estimates of sky-view fraction, canopy transmissivity, and longwave enhancement could be obtained. Under favorable meteorological conditions, validation against sky-view fraction data from hemispherical photographs yielded an RMSE of 0.03 (i.e., $3 \%$ ). Irradiance measurements under heterogeneous canopy cover revealed strong spatial coherence between longwave radiation enhancement, shortwave radiation attenuation, and sky-view fraction on overcast days. Under clear-sky conditions, however, sun flecks caused highly variable shortwave radiation transmissivity patterns. This study demonstrates the potential of handheld radiometer surveys to deliver valuable spatially distributed datasets of collocated canopy structure and subcanopy irradiance which can be used (i) as reference data for alternative approaches to derive canopy structure parameters, (ii) to improve modeling of subcanopy radiation across a wide range of canopy distributions, and (iii) to support respective model upscaling efforts.
\end{abstract}

\section{Introduction}

The three-dimensional structure of forest canopy largely controls the subcanopy radiation regime, masking the ground from shortwave radiation and enhancing the longwave radiation input (Essery et al. 2008a; Link et al. 2004; Lundquist et al. 2013; Sicart et al. 2004).

\footnotetext{
Supplemental information related to this paper is available at the Journals Online website: https://doi.org/10.1175/JHM-D-180158.s1.
}

Corresponding author: G. Mazzotti, giulia.mazzotti@slf.ch
Radiative fluxes are a key component of the subcanopy energy balance, dictating ecohydrological processes such as plant growth, evapotranspiration, soil moisture, and snow cover dynamics (Battaglia et al. 2002; Gray et al. 2002; Hardy et al. 2004). Including these processes in land surface models requires accurate characterization of all-wave irradiance to the forest floor over a wide range of spatial scales, which can only be achieved if radiative fluxes are linked to structural characteristics of the overhead canopy (Hardy et al. 2004; Lawler and Link 2011; Link et al. 2004; Musselman et al. 2012). Representing spatial variability of canopy structure and subcanopy irradiance are thus intertwined problems. 
Canopy radiative transfer is of particular interest in the context of snowmelt prediction in forested areas, where net radiation has been identified as a major driver (Link and Marks 1999; Mahat and Tarboton 2012). As subcanopy radiation dynamics depend on canopy density, solar angle relative to the spatial layout of the canopy, and atmospheric conditions (e.g., Hardy et al. 2004), contrasting radiation regimes can result in both delayed and accelerated snowmelt in forests compared to open areas (e.g., Lundquist et al. 2013). Many studies have highlighted the need to better understand spatiotemporal subcanopy irradiance dynamics, especially in discontinuous forests (Hardy et al. 2004; Musselman et al. 2012), and the value of spatially distributed experimental data to inform radiative transfer models (Link and Marks 1999). Common parameterizations of radiative transfer processes draw on experimental data acquired at fixed locations representative of the site scale (e.g., Essery et al. 2008a; Link and Marks 1999; Mahat and Tarboton 2012; Reid et al. 2014b). These data capture the temporal dynamics of radiative fluxes, but provide limited spatial coverage. Spatially distributed subcanopy irradiance datasets are rarely available and challenging to obtain (Seyednasrollah et al. 2013), but they are needed to support the integration of radiative transfer schemes over coarser grid resolutions and to assess model performance at large scales (Essery et al. 2009) and across heterogeneous forest cover (Broxton et al. 2015).

The radiation input to the forest floor at a given location is strongly controlled by the sky-view fraction, that is, the visible portion of sky in the hemispherical view, weighted to account for elevation angle [Hardy et al. 2004; cf. Essery et al. (2008a) for a mathematical formulation]. Sky-view fraction dictates the relative contribution of longwave radiation from the sky passing through canopy gaps to that emitted by the surrounding canopy (Essery et al. 2008a; Pomeroy et al. 2009; Sicart et al. 2004), modulates diffuse shortwave irradiance to the forest floor, and correlates with the occurrence of direct insolation (Sicart et al. 2004; Lawler and Link 2011). Sky-view fraction is most commonly derived from analysis of optical hemispherical photographs (HP). There are, however, shortcomings inherent to the method, such as inaccuracies related to image exposure (Beckschäfer et al. 2013; Zhang et al. 2005) and selection of a binarization threshold (Jonckheere et al. 2005; Nobis and Hunziker 2005), which cannot be fully mitigated by standardized protocols and automated processing (Glatthorn and Beckschafer 2014; Song et al. 2014; Pueschel et al. 2012; Ishida 2004). In addition, HP is not suited to provide spatially distributed measurements. Recent advances in lidar technology have motivated attempts to replace optical hemispherical photography by synthetic images derived from both terrestrial (Hancock et al. 2014; Jupp et al. 2009; Seidel et al. 2012) and aerial (Varhola et al. 2012; Moeser et al. 2014) scans. While these methods are certainly promising, their applicability is restricted to datasets of very high point densities, and their transferability to datasets different than those used for their development is still to be validated. Moreover, the extrapolation of point-based parameters to represent the spatial resolution of typical land surface models is yet to be explored (Essery et al. 2008b; Friesen et al. 2015; Varhola and Coops 2013).

This study presents a novel inverse approach to experimentally investigate the spatial variability of canopy structure and subcanopy irradiance. We developed a radiometer setup mounted on a stabilizing gimbal, specifically designed for efficient, spatially distributed measurements of subcanopy radiation and sky-view fraction along forest transects. The method was tested on data collected throughout the winter season 2017/18 at a variety of forest sites and for a wide range of meteorological conditions, with the objectives

1) to introduce the concept and the implementation of the new approach, which we refer to as handheld radiometer surveys (HRS);

2) to assess the accuracy of sky-view fraction estimates based on HRS under a variety of meteorological conditions and with reference to a traditional method (HP);

3) to demonstrate the application of HRS to spatially continuous recording of sky-view fraction; and

4) to showcase how the HRS approach can be applied to analyze canopy radiative transfer on a spatially distributed scale, with reference to canopy structure and meteorological conditions.

\section{Data and methods}

\section{a. Theoretical background}

The handheld radiometer survey methodology uses measurements of the meteorological variables involved in radiative transfer to infer sky-view fraction $V_{f}$, longwave radiation enhancement $\lambda$, and shortwave radiation transmissivity $\tau$ at any specific forest site (FS). Below-canopy downwelling long- and shortwave radiation measurements performed along forest transects [i.e., $\mathrm{LW}_{\downarrow \mathrm{FS}}$ $\left.\left(\mathrm{W} \mathrm{m}^{-2}\right), \mathrm{SW}_{\downarrow \mathrm{FS}}\left(\mathrm{W} \mathrm{m}^{-2}\right)\right]$ are coupled to concurrent radiation and air temperature measurements at a nearby reference open site [i.e., $\mathrm{LW}_{\downarrow} \mathrm{OS} \quad\left(\mathrm{W} \mathrm{m}^{-2}\right), \mathrm{SW}_{\downarrow} \mathrm{OS}$ $\left.\left(\mathrm{W} \mathrm{m}^{-2}\right), T_{a \mathrm{OS}}(\mathrm{K})\right]$, the former two of which serve as proxies for respective above canopy conditions. As demonstrated in the results section, this approximation is sufficiently accurate for the purpose of our work. Canopy radiative transfer is therefore evaluated by direct comparison of below- and outside-canopy radiation. 
Longwave radiation emittance by the canopy is generally larger than atmospheric longwave radiation (e.g., Pomeroy et al. 2009; Sicart et al. 2004), leading to longwave enhancement $\lambda$ :

$$
\lambda \approx \frac{\mathrm{LW}_{\downarrow \mathrm{FS}}}{\mathrm{LW}_{\downarrow \mathrm{OS}}} .
$$

Incoming shortwave radiation to the forest floor constitutes a fraction $\tau$ of the above-canopy incoming shortwave radiation, typically referred to as the canopy transmissivity (e.g., Hardy et al. 2004; Link et al. 2004):

$$
\tau \approx \frac{\mathrm{SW}_{\downarrow \mathrm{FS}}}{\mathrm{SW}_{\downarrow \mathrm{OS}}} .
$$

Sky-view fraction at any within-forest location $V_{f \mathrm{FS}}$ can be inferred from both long- and shortwave radiation measurements. Below-canopy longwave irradiance $L W_{\downarrow \mathrm{FS}}$, consisting of atmospheric and canopy components $\left(\mathrm{LW}_{\downarrow \text { sky }}, \mathrm{LW}_{\downarrow \text { can }}\right)$, is given by

$$
\mathrm{LW}_{\downarrow \mathrm{FS}}=V_{f \mathrm{FS}} \mathrm{LW}_{\downarrow \mathrm{sky}}+\left(1-V_{f \mathrm{FS}}\right) \mathrm{LW}_{\downarrow \text { can }} .
$$

Longwave radiation emitted by the canopy is parameterized by the Stefan-Boltzmann law, assuming the canopy to be an ideal emitter (i.e., emissivity $=1$ ) and approximating its effective temperature by the air temperature measured at the reference open site. The above assumptions are commonly used [e.g., by Essery et al. (2008a), Webster et al. (2017), and Sicart et al. (2004)], and also reassessed further below (cf. sections $3 \mathrm{a}$ and $4 \mathrm{c}$ ). With these assumptions, Eq. (2.3) transforms into

$$
\mathrm{LW}_{\downarrow \mathrm{FS}}=V_{f \mathrm{FS}} \mathrm{LW}_{\downarrow \text { sky }}+\left(1-V_{f \mathrm{FS}}\right) \sigma T_{a \mathrm{OS}}^{4},
$$

where $\sigma$ denotes the Stefan-Boltzmann constant $(5.67 \times$ $10^{-8} \mathrm{~W} \mathrm{~m}^{-2} \mathrm{~K}^{-4}$ ).

The atmospheric component can be replaced by the open-site measurement if sky-view fraction at the open site $\left(V_{f \circ s}\right)$ equals 1 . This is true for flat areas, however terrain shading by the surrounding topography can be considerable at mountainous sites, in which case $V_{f \circ S}$ should not be neglected:

$$
\mathrm{LW}_{\downarrow \mathrm{OS}}=V_{f \mathrm{OS}} \mathrm{LW}_{\downarrow \mathrm{sky}}+\left(1-V_{f \mathrm{OS}}\right) \sigma T_{a \mathrm{OS}}^{4} .
$$

In Eq. (2.5), the longwave radiation from the surrounding terrain is estimated applying the same assumptions as in Eq. (2.4). This is typically adequate for sites where terrain shading is small $\left(V_{f \circ S}>0.9\right)$ or predominantly obscured by nearby forest.
Solving Eq. (2.5) for $\mathrm{LW}_{\downarrow \text { sky }}$ allows Eq. (2.4) to be inverted to yield sky-view fraction at the forest site:

$$
V_{f \mathrm{FS}}=V_{f \mathrm{O}} \frac{\left(\mathrm{LW}_{\downarrow \mathrm{FS}}-\sigma T_{a \mathrm{OS}}^{4}\right)}{\left(\mathrm{LW}_{\downarrow \mathrm{OS}}-\sigma T_{a \mathrm{OS}}^{4}\right)} .
$$

Alternatively, $V_{f \mathrm{FS}}$ can be calculated from shortwave radiation data. In the presence of a homogeneous cloud cover, solar radiation is only diffuse and penetrates through canopy gaps in the same way as atmospheric longwave radiation. As a consequence, shortwave transmissivity coincides with sky-view fraction (e.g., Sicart et al. 2004). Correcting for effects of the surrounding terrain yields:

$$
V_{f \mathrm{FS}}=V_{f \mathrm{OS}} \frac{\mathrm{SW}_{\downarrow \mathrm{FS}}}{\mathrm{SW}_{\downarrow \mathrm{OS}}} .
$$

In the following, the subscript FS is omitted, with $V_{f}$ referring to local subcanopy sky-view fraction. We use $V_{f, \text { LW }}$ to refer to sky-view fraction values obtained from longwave radiation measurements, while $V_{f, \mathrm{sw}}$ denotes sky-view fraction derived from shortwave radiation data.

\section{b. Instrumentation}

A portable handheld radiometer setup was designed for the scope of this study. It includes a pair of Kipp \& Zonen radiometers (a CMP3 pyranometer and a CGR3 pyrgeometer), mounted onto a commercial motorized Zhiyun Crane 2 camera gimbal. The gimbal ensured accurate levelling of the sensors at all times, independent of the movement of the carrying person. Given the sensitivity of the radiation measurements to even small inclination angles (Bogren et al. 2016), the active gimbal stabilization was key to achieving a high quality of the measurements. The wires connecting the sensors to the datalogger (Campbell Scientific CR1000) were fixed to the gimbal to minimize disturbance of the motors. The setup was further equipped with a push button to allow recording of timestamps alongside the measurements. Figure 1 shows the setup components and its deployment in the field.

The stationary setup established for the reference open-site measurements also included a pair of Kipp \& Zonen CMP3 and CGR3 radiometers as well as a Vaisala HMP60 air temperature and relative humidity sensor in a naturally aspirated six-plate radiation shield. The instrumentation was designed to allow easy transport and quick installation. The HMP60 was fixed to a pole $2 \mathrm{~m}$ above the snow surface while the radiation sensors were mounted 

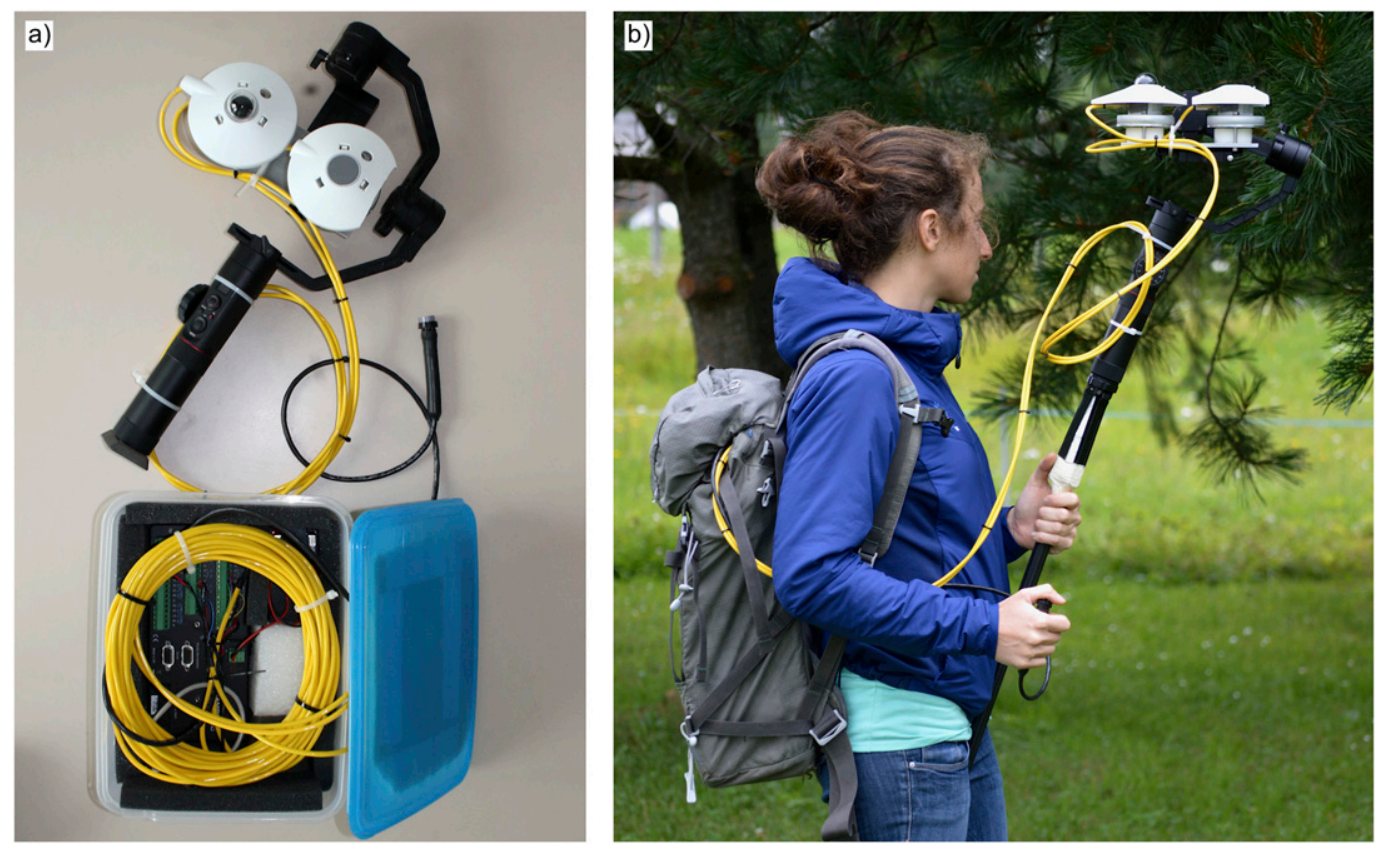

FIG. 1. (a) Components of the handheld radiometer setup including radiation sensors, push button, camera gimbal, and box containing batteries and a datalogger. (b) Operation of the handheld radiometer setup in the field.

on a tripod equipped with a ball head for accurate levelling.

\section{c. Field areas and campaigns}

Data were acquired as part of a larger forest-snow monitoring effort during the 2017/18 winter season in five field areas in the Eastern Swiss Alps. These were situated around Davos (Laret, Wolfgang, Drusatscha) and in the Engadin valley (Flin, Laresgia), each corresponding to one reference open site (Fig. 2). Measurement plots were located in flat topography within $1 \mathrm{~km}$ of the open site. They comprised closed and discontinuous alpine coniferous forests of spruce, pine and larch, the most common tree species in the study region. The plots consisted of eight transects of 40-m length each, arranged to form a grid of four parallel lines orthogonally intersected by another set of four parallel lines (Fig. 2). All intersection points were marked on the ground for exact spatial alignment with subsequent hemispherical imagery, and manually georeferenced with the help of a lidar-based canopy height model (cf. section 2e) and aerial imagery available for the sites. Meteorological conditions in form of synoptic weather observations were recorded to categorize cloud cover during each survey, distinguishing between clear sky, partial cloud cover and overcast conditions. We further computed apparent sky emittance $\varepsilon_{A}$ (Marty and Philipona 2000) as quantitative indicator of cloudiness (cf. online supplemental material, S1 and S2).
Data acquisition took place on 20 days, where most plots were surveyed only once, but a few were revisited to demonstrate the reproducibility of the HRS measurements. Two campaigns included measurements along additional linear transects ( $\sim 200-\mathrm{m}$ length) at the sites Laret and Flin. In this case, validation points were marked every $10 \mathrm{~m}$ along transect. Moreover, two fixed sensor assemblies were deployed at a forested and an open location in Davos Laret for a multiday campaign during four consecutive clear-sky days in late April, aiming to explore potential effects of diurnal radiation and temperature cycles on the HRS. Further specifications of the sites and the field campaigns can be found in the supplemental material (S2).

\section{d. Handheld radiometer surveys and data processing}

The handheld radiometer assembly was carried along the transects at a constant slow walking pace of approximately $v_{\mathrm{HRS}} \approx 0.15 \mathrm{~m} \mathrm{~s}^{-1}$, with time stamps being recorded at each intersection point. In this feasibility test setting, the slow pace was chosen to allow sufficient time for the sensor to respond to small-scale changes of the radiative conditions. Following this procedure, each plot could be surveyed within $40 \mathrm{~min}$, and intersection points yielded repeated measurements at the same location. Data were recorded at 1-s intervals by both the handheld radiometer assembly and the open-site reference station installed for the duration of the forest surveys. 


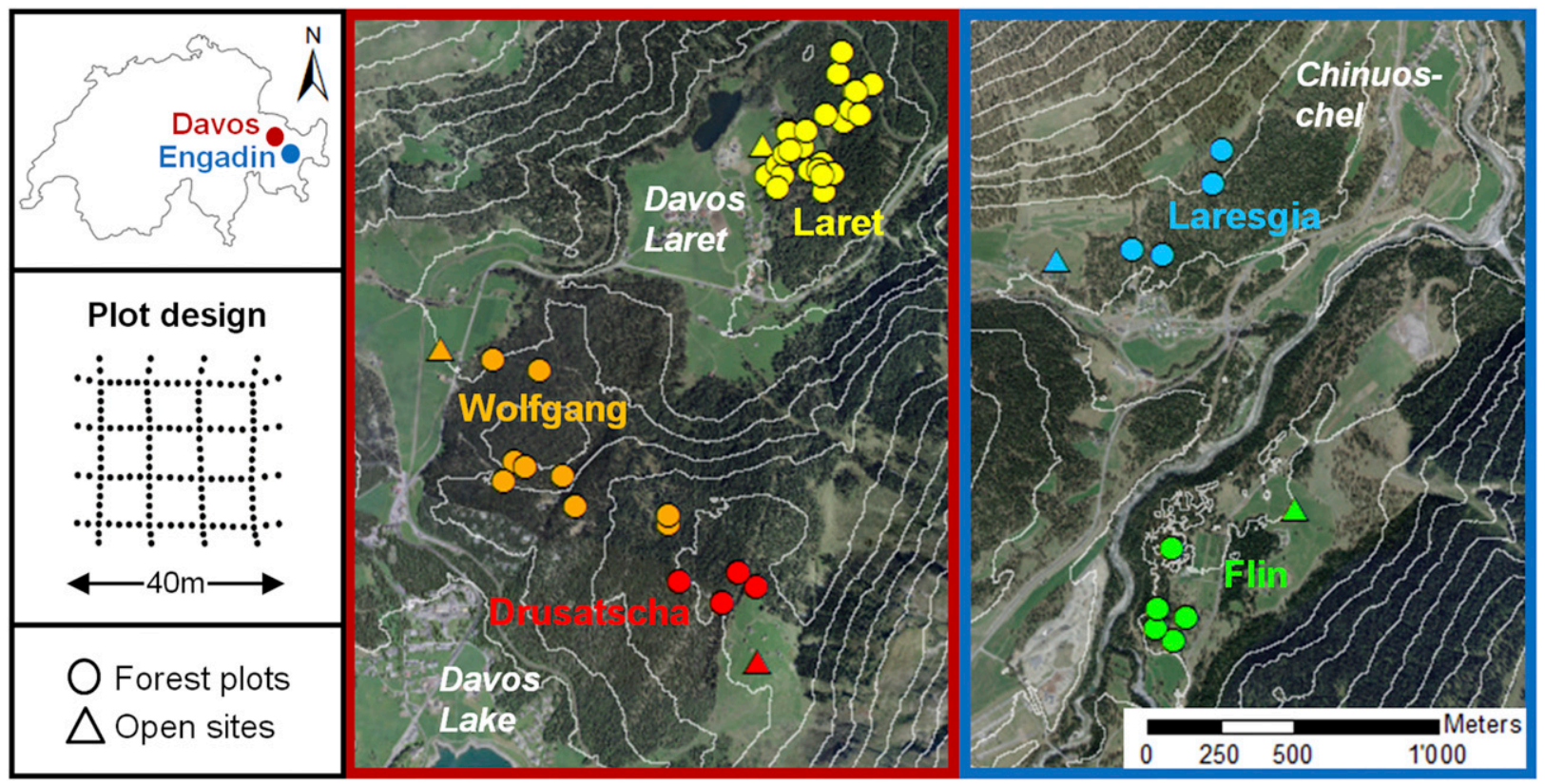

FIG. 2. Overview of the field areas in Davos and the Engadin valley and schematic illustrating the design of the forest plots. The colors of the forest plots coincide with the associated reference open site.

Data postprocessing was minimal, consisting of the following steps:

1) Temporal synchronization: Data recorded by the two sensor setups were matched based on their logger time stamps.

2) Computation of target variables: Time series of $\lambda, \tau$, and $V_{f}$ were obtained by applying Eqs. (2.1), (2.2), and (2.6), respectively.

3) Conversion to the spatial dimension: The time series were converted to yield canopy parameters along transect distance $x$ assuming a constant walking velocity on each segment between consecutive intersection/validation points $M_{n}$ and $M_{n+1}$ :

$$
\begin{gathered}
v_{\mathrm{HRS}}=\frac{\left(x_{M_{n+1}}-x_{M_{n}}\right)}{\left(t_{M_{n+1}}-t_{M_{n}}\right)}, \\
{\left[V_{f}(x), \tau(x), \lambda(x)\right]=v_{\mathrm{HFS}}\left[V_{f}(t), \tau(t), \lambda(t)\right] .}
\end{gathered}
$$

4) Data georeferencing: All datasets were georeferenced by matching data from Eq. (2.9) to the known geolocation of the corresponding validation points.

The resulting datasets comprise sky-view fraction, shortwave radiation transmissivity, longwave radiation enhancement, location, and time of measurement for each data point.

\section{e. Canopy structure data from hemispherical photography and airborne lidar}

Hemispherical photography was applied to create a reference dataset against which the performance of the HRS method could be tested. Images were acquired at all transect intersection points using a Canon EOS 600D SLR digital camera equipped with a SIGMA $4.5 \mathrm{~mm}$ F2.8 EX DC circular fisheye lens. Several images of varying exposure times were taken at each location. A small number of sites were revisited and image acquisition repeated to test the consistency of HP-based skyview fraction estimates under varying meteorological conditions.

Processing of the hemispherical images required:

1) Image selection: A visual assessment of image quality allowed the image with the most suitable exposure time to be selected for each validation point, with good contrast between sky and canopy being the key selection criterion.

2) Image thresholding and binarization: For comparison purposes, thresholding was performed both manually and automatically based on Otsu (1979).

3) Computation of $V_{f}$ : Calculations of $V_{f}$ followed Essery et al. (2008a).

Step 2 revealed a number of images for which the results from manual thresholding were not satisfactory, for reasons such as strong brightness gradients across 
the frame. These cases $(<10 \%$ of the images) were discarded from subsequent data analysis. A subsample of HP images was processed by two people independently in order to test the impact of human subjectivity on the results. Hemispherical photographs were also acquired at all reference open sites to enable the application of Eqs. (2.5), (2.6), and (2.7). Acquisition and processing of HP are detailed further in the supplemental material (S3).

In addition to HP, a detailed dataset acquired in 2010 with helicopter-borne lidar (up to 36 points per meter squared) is available for the Laret site, presented and extensively used by Moeser et al. (2014) and Webster et al. (2017). Here, we rely on these data to create alternative canopy metrics to be contrasted to the HRS. We considered two parameters:

1) Vertically projected canopy-cover fraction $\left(\mathrm{CC}_{f}\right)$ : A canopy height model $(0.25-\mathrm{m}$ resolution) was generated from the lidar point cloud by the approach presented in Khosravipour et al. (2014), and binarized based on a 2-m height threshold. We then determined $\mathrm{CC}_{f}$ for each grid cell over a circular domain with a radius of $2 \mathrm{~m}$.

2) Sky-view fraction based on synthetic hemispherical images $\left(V_{f, \mathrm{SHI}}\right)$ : The method described by Moeser et al. (2014) and associated software were applied to convert the lidar point cloud into synthetic hemispherical images (SHI), which we then used to derive $V_{f, \mathrm{SHI}}$ in the same way as for the real HP.

These metrics were computed over the extent of two different surveyed plots (cf. supplemental material S4), where the 2-m spacing yielded spatially continuous datasets.

\section{Results}

\section{a. Sky-view fraction estimates from repeated handheld radiometer measurements}

Repeated measurements at intersection points allowed the consistency of sky-view fraction estimates from HRS to be evaluated. As performance is expected to vary depending on the meteorological conditions during the survey, we considered four separate cases: (i) clear sky, stable; (ii) clear sky, transient; (iii) overcast; and (iv) partial cloud cover, based on the synoptic cloud cover classification (section 2c). In case of clear sky, we discriminated between stable conditions $\left(\Delta T_{a \mathrm{OS}} \leq 1^{\circ} \mathrm{C}\right.$ and $\Delta \mathrm{SW}_{\downarrow \mathrm{FS}} \leq 200 \mathrm{Wm}^{-2}$ between repeated measurements) and transient conditions $\left(\Delta T_{a \mathrm{OS}}>1^{\circ} \mathrm{C}\right.$ and $\Delta \mathrm{SW}_{\downarrow \mathrm{FS}}>200 \mathrm{~W} \mathrm{~m}^{-2}$ between repeated measurements), aiming at identifying rapid changes in either $T_{a \mathrm{OS}}$ and/or $\mathrm{SW}_{\downarrow \mathrm{FS}}$ over the course of the survey.

Deriving sky-view fraction from longwave radiation measurements $\left[V_{f, \mathrm{LW}}\right.$; Eq. (2.6)], the best consistency was achieved under stable clear-sky conditions with a root-mean-square error (RMSE) of 0.028 (Fig. 3a, Table 1). In contrast, performance deteriorated when the onset of direct insolation occurred between repeated visits (Fig. 3b, transient conditions). However, the increased RMSE of 0.075 (Table 1) dropped to 0.046 when the analysis was restricted to points with $\mathrm{SW}_{\downarrow \mathrm{FS}}<$ $400 \mathrm{~W} \mathrm{~m}^{-2}$. This affirms observations by Webster et al. (2017), who suggested that the approximation of canopy temperature by open-site air temperature is no longer appropriate above this threshold. Relative to stable clear-sky conditions, overcast conditions caused a small reduction in consistency (RMSE $=0.045$, Fig. 3c, Table 1), but performance was considerably worse in the presence of a partial cloud cover $(\mathrm{RMSE}=0.087$; Fig. 3d, Table 1). Sky-view fraction estimates based on shortwave radiation data [ $V_{f, \mathrm{Sw}}$; Eq. (2.7)] were also highly consistent during overcast conditions, featuring an RMSE of 0.027 only (Fig. 4, Table 1). However, this approach had to be restricted to plots surveyed when the occurrence of direct radiation could be excluded due to the homogeneous cloud cover.

A stationary pyrgeometer at any forest location should ideally yield sky-view fraction estimates $\left(V_{f, \mathrm{LW}}\right)$ that are constant in time. We tested the effect of solar heating under clear-sky conditions on the temporal stability of $V_{f, \mathrm{LW}}$ estimates, using data from the stationary multiday campaign. HP analysis yielded $V_{f, \mathrm{HP}}=0.17$ at the location of the stationary forest sensor (i.e., a dense canopy site). The time series of HRS-based sky-view fraction estimates shows distinct daily cycles (Fig. 5a, blue curve). The $V_{f, \mathrm{LW}}$ estimates are rather stable and consistent with $V_{f, \mathrm{HP}}$ early in the day, but experience an increase in the forenoon when the open-site air temperature becomes higher than subcanopy air temperature. HRS-derived $V_{f, \text { LW }}$ decreases after a peak in the afternoon, and transitions into underestimating $V_{f, \mathrm{HP}}$ during evening and early night hours, as the canopy retains the absorbed heat longer than the air due to its heat capacity. Consistency with HP-based sky-view fraction is re-achieved at night, when thermal equilibrium between canopy and air is reached.

The stationary forest site setup was also equipped with an air temperature sensor (compared to the open site sensor in Fig. 5b). Replacing the open-site air temperature by withinforest air temperature as a proxy for canopy temperature improved the temporal stability of the sky-view fraction 
a)

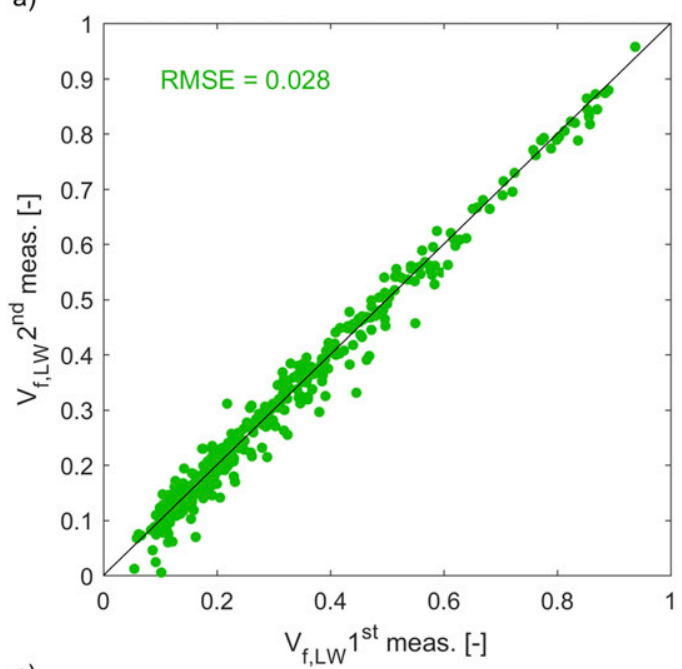

c)

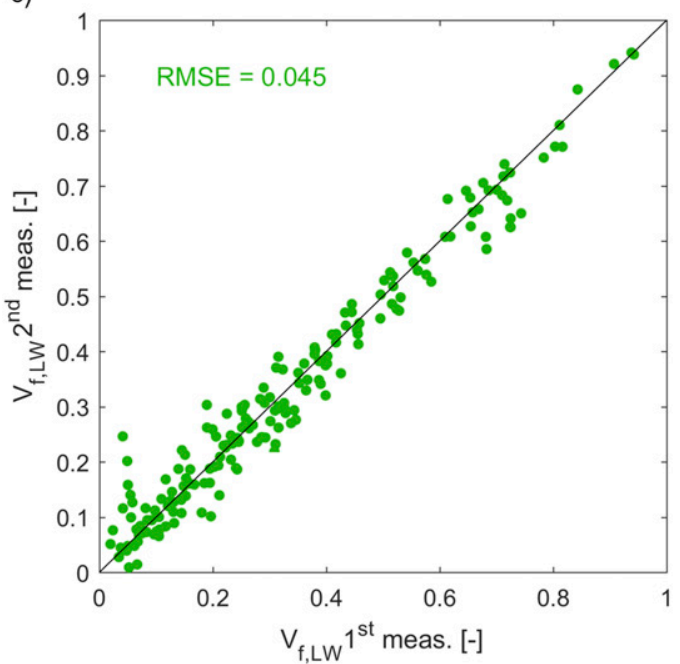

b)

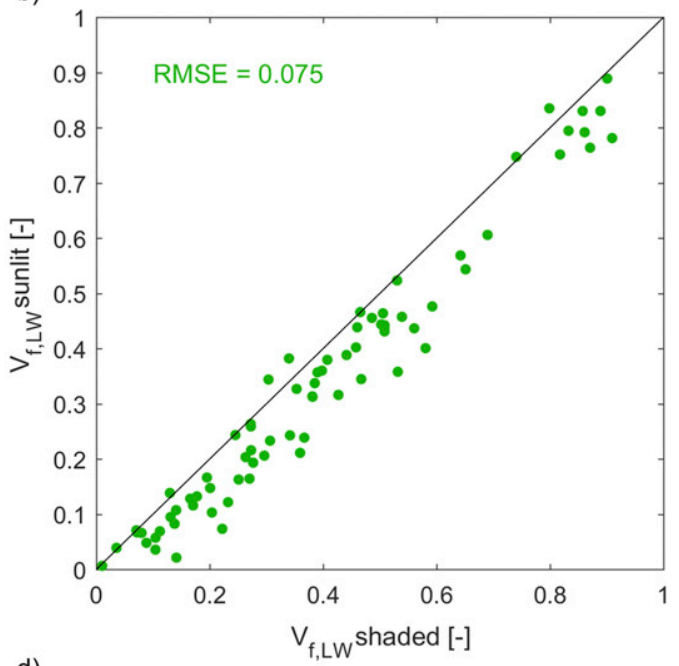

d)

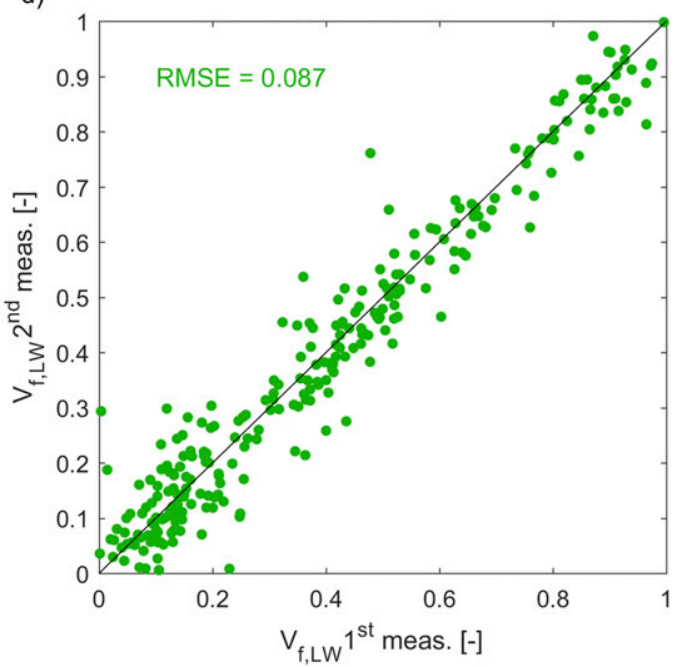

FIG. 3. Consistency of repeated sky-view fraction measurements derived from longwave radiation data $\left(V_{f, \mathrm{LW}}\right)$ under (a) stable clear-sky conditions, (b) transient clear-sky conditions, (c) overcast conditions, and (d) partial cloud cover.

calculations, dampening daily cycles (Fig. 5a, green curve) and eliminating its overestimation. However, underestimation of reference sky-view fraction by the HRS data was still observed during afternoon and evening hours.
Combining data from both temperature sensors yielded the smallest overall bias between HRS-based and HP-based sky-view fraction estimates over the measurement period (Fig. 5a, red curve).

TABLE 1. Statistical measures of the fit between repeated sky-view fraction measurements by HRS for different meteorological conditions: RMSE, mean absolute error (MAE), and correlation coefficient (Pearson's $R$ ).

\begin{tabular}{cccc}
\hline \hline Sky-view fraction dataset and meteorological conditions & RMSE & MAE & Pearson's $R$ \\
\hline$V_{f, \mathrm{LW}}$, clear sky, stable conditions & 0.028 & 0.021 & 0.991 \\
$V_{f, \mathrm{LW}}$, clear sky, transient conditions & 0.075 & 0.062 & 0.954 \\
$V_{f, \mathrm{LW}}$, overcast conditions & 0.045 & 0.033 & 0.981 \\
$V_{f, \mathrm{LW}}$, partial cloud cover & 0.087 & 0.057 & 0.958 \\
$V_{f, \mathrm{SW}}$, overcast conditions & 0.027 & 0.018 & 0.992 \\
\hline
\end{tabular}




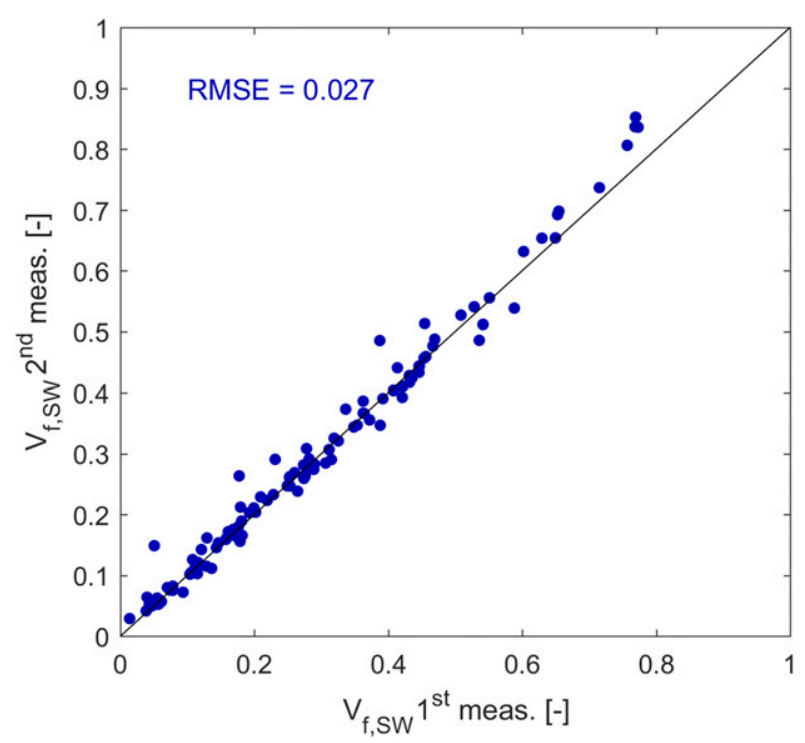

FIG. 4. Consistency of repeated sky-view fraction measurements derived from shortwave radiation data $\left(V_{f, \mathrm{sw}}\right)$ under overcast conditions.

\section{b. Validation of sky-view fraction estimates against hemispherical images}

HRS-based sky-view fraction estimates were validated against reference values from HP analysis. Given the known potential biases of the HRS method under unfavorable meteorological conditions as outlined above, the comparison was restricted to data points that were acquired under "optimal" field conditions. Based on results presented in section $3 \mathrm{a}$, these comprised (i) plots surveyed on clear-sky days prior to direct insolation
$\left(\mathrm{SW}_{\downarrow \mathrm{FS}}<400 \mathrm{~W} \mathrm{~m}^{-2}\right)$, in which case longwave radiation measurements were used to derive sky-view fraction $V_{f, \mathrm{LW}}$, or (ii) plots surveyed on overcast days, where sky-view fraction was computed based on shortwave radiation data $V_{f, \text { Sw }}$. In these two cases, sky-view fraction could be determined within less than $5 \%$ difference to the reference data (RMSEs of 0.035 and 0.025 , respectively; Figs. 6a,b, Table 2). Discrepancies are consistent throughout the captured range of $V_{f}(0.05-0.8)$ and are of the same order of magnitude as equivalent errors related to sensor accuracy.

Errors associated with the analysis of hemispherical photographs were evaluated to provide a baseline for the accuracy assessment of the HRS method. We found very good consistency of sky-view fraction estimates from two independent sets of HP acquired at the same locations on different days, selected and binarized manually by the same person (RMSE $=0.023$; Fig. 6 c, Table 2 ). Sky-view fraction estimates resulting from different postprocessing of the same image acquisition agreed less well, with RMSE $=0.041$ between manual thresholding by two different persons and RMSE $=0.026$ between manual and automatic thresholding (Fig. 6d, Table 2). In all cases, the errors are of similar magnitude as those observed when comparing sky-view fraction data based on HP and HRS.

\section{c. Application of HRS to spatially continuous characterization of canopy structure}

The gridded design of the plots yielded quasi twodimensional sky-view fraction maps, representing spatial patterns of $V_{f}$. Figure 7 contrasts repeated HRS acquisitions at two sites, revealing very consistent a)

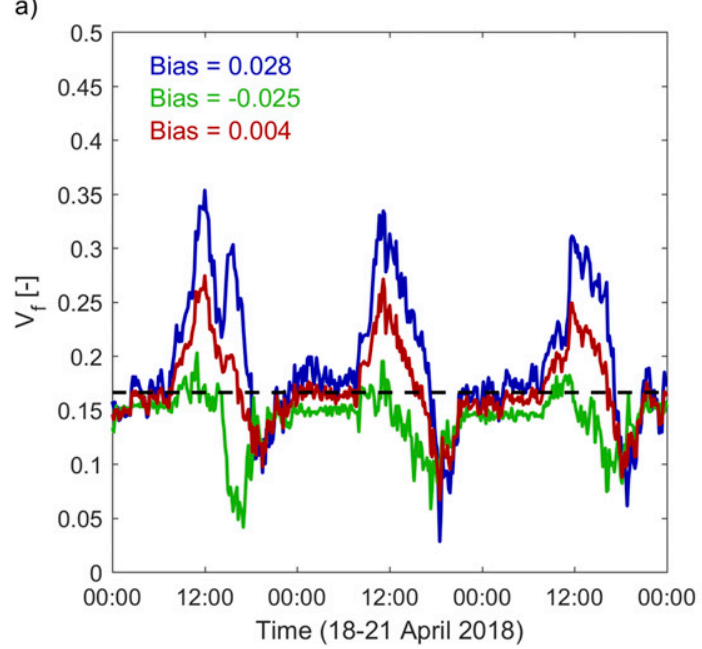

b)

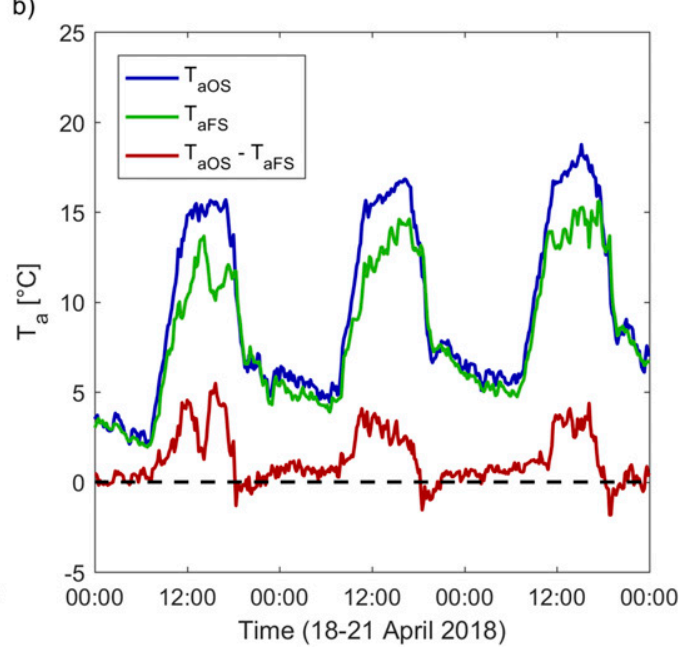

FIG. 5. (a) Sky-view fraction $\left(V_{f, \mathrm{LW}}\right)$ derived from the multiday campaign deploying a fixed sensor setup installation in dense forest, using air temperatures measured at the open (blue) and forested (green) sites, and the average of the two (red), as proxies for canopy temperature. The black line marks the sky-view fraction derived from $\mathrm{HP}\left(V_{f, \mathrm{HP}}=0.17\right)$. (b) Air temperature data from the fixed installations in dense forest and open sites and deviations between the two. 
a)

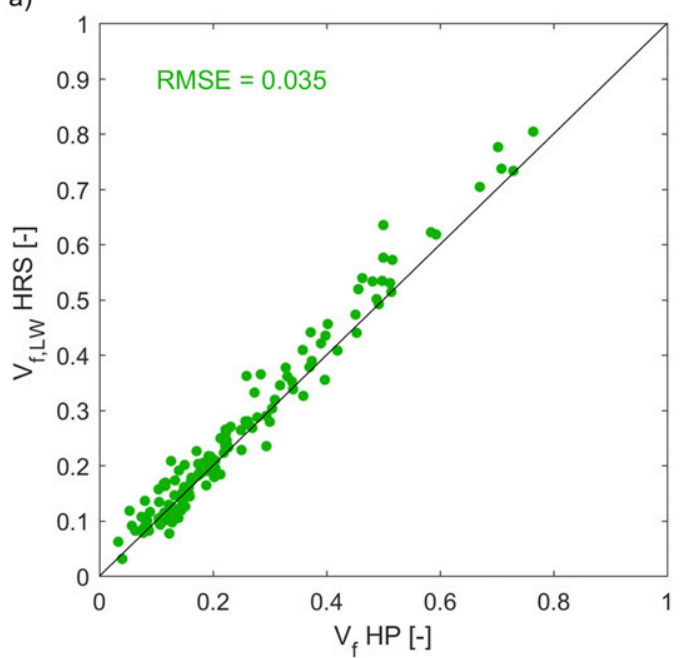

c)

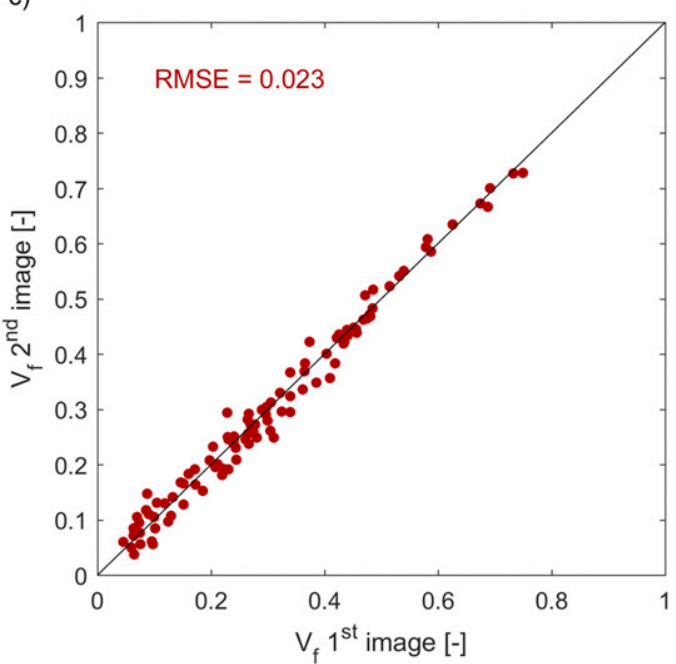

b)

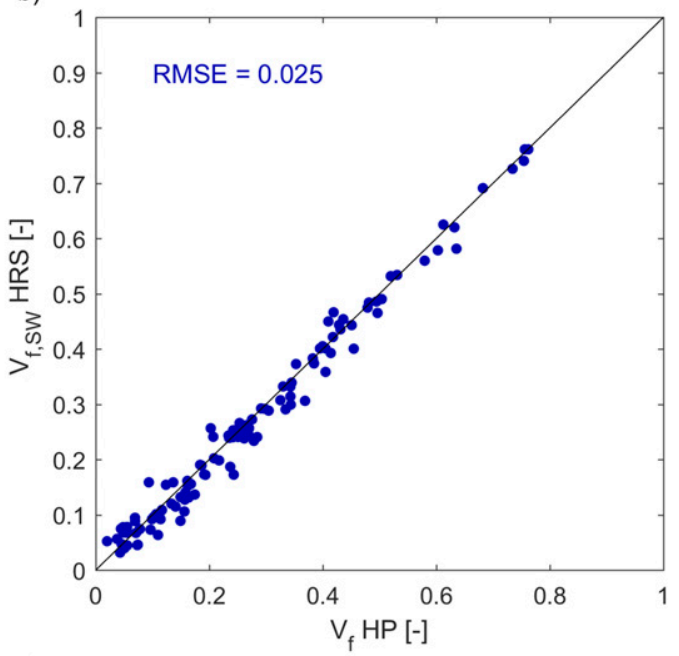

d)

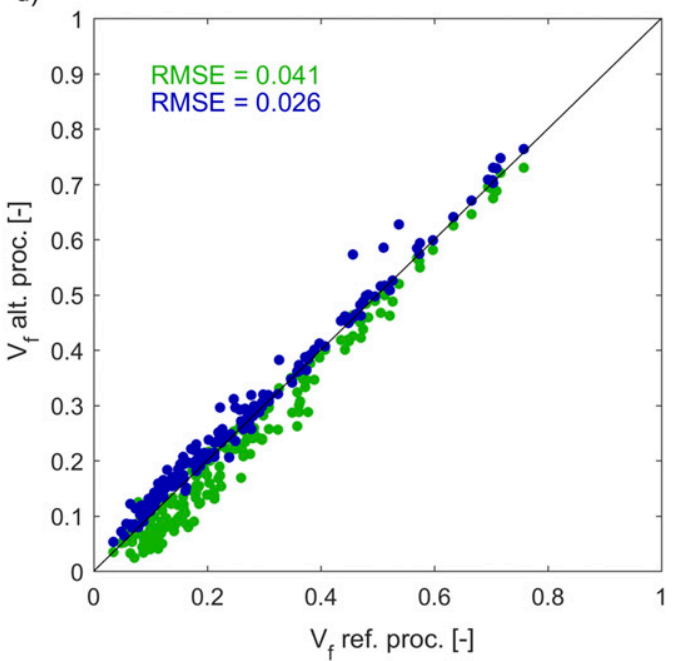

FIG. 6. Comparison of sky-view fraction values derived from (a) longwave $V_{f, \mathrm{LW}}$ and (b) shortwave $V_{f, \text { sw }}$ radiation data under optimal meteorological conditions to reference values computed from hemispherical photography, contrasted with the consistency of sky-view fraction derived from hemispherical images between (c) two independent image acquisitions and (d) between alternative processing of the same image, i.e., manual processing by two different people (green) and manual vs automatic thresholding (blue).

patterns for surveys using alternative radiation data (Fig. 7a) and occurring at different times of the same day (Fig. 7b). The examples also illustrate that although the plots only cover areas of $40 \mathrm{~m} \times 40 \mathrm{~m}$, they may span most of the range of possible $V_{f}$ values, indicating the parameter's strong spatial variability.

To illustrate how HRS data can be used to complement alternative sources of canopy structure information, we compare the resulting sky-view fraction estimates to sky-view fraction and canopy-cover fraction derived from airborne lidar data (section 2e). Lidar- and HRS-based variables appear to be correlated ( $R=0.93$ and 0.86 for $V_{f, \mathrm{SHI}}$ and $1-\mathrm{CC}_{f}$, respectively), but the high RMSE values (0.09 and 0.34$)$ reveal distinct differences between these variables. Sky-view fraction estimates derived from lidar data exceed radiometerbased values for small sky-view fraction values $\left(V_{f}<\right.$ $0.5)$, but the opposite holds true for larger $V_{f}$ values (Fig. 8a). Canopy-cover fraction is based on a vertical perspective and therefore differs considerably from the HRS-based sky-view fraction (Fig. 8b), which is reflected in a bimodal distribution of the variable, while sky-view fraction appears to be more equally distributed.

\section{d. Application of HRS to analysis of spatially distributed canopy radiative transfer}

Spatial variability of subcanopy irradiance relates to collocated variations in canopy structure, but is also 
TABLE 2. Statistical measures of the fit between different sky-view fraction datasets: RMSE, mean absolute error (MAE), and correlation coefficient (Pearson's $R$ ).

\begin{tabular}{lccc}
\hline \hline \multicolumn{1}{c}{ Sky-view fraction dataset comparisons } & RMSE & MAE & Pearson's $R$ \\
\hline HRS-based $V_{f, \text { LW }}$ (clear sky, stable conditions) vs reference HP & 0.035 & 0.025 & 0.985 \\
HRS-based $V_{f, \text { SW }}$ (overcast conditions) vs reference HP & 0.025 & 0.019 & 0.990 \\
Two repeated HP image acquisitions processed by the same person & 0.024 & 0.019 & 0.991 \\
Reference manual HP processing vs independent HP processing by other person & 0.041 & 0.034 & 0.989 \\
Reference manual HP processing vs automatic HP processing & 0.027 & 0.020 & 0.993 \\
\hline
\end{tabular}

strongly affected by meteorological conditions. Subcanopy longwave and shortwave irradiance feature inverse spatial patterns under overcast conditions (Fig. 9), where denser canopy is associated with longwave radiation maxima and shortwave irradiance minima. As a result, variations in sky-view fraction computed from longwave radiation data reflect patterns of shortwave radiation transmissivity along the entire transect. Longwave enhancement features the inverse spatial trend, which is, however, weak and restricted to a very narrow range, due to the similarity of atmospheric and canopy longwave components in overcast skies. Segregation of these components is more distinct for clear skies, causing stronger and more variable longwave enhancement (Fig. 10). Direct insolation also occurs in the absence of clouds, creating complex transmissivity patterns dictated by the interplay between sun position and canopy geometry. The resulting strong variability in transmissivity along the transect reflects alternating sun flecks and shaded forest ground and, as expected, no longer shows any correlation to the sky-view fraction.

We finally showcase how HRS data can reveal further insights into dependencies between canopy structure, radiative transfer and meteorological conditions in Fig. 11. Sky-view fraction and canopy radiative transfer a)

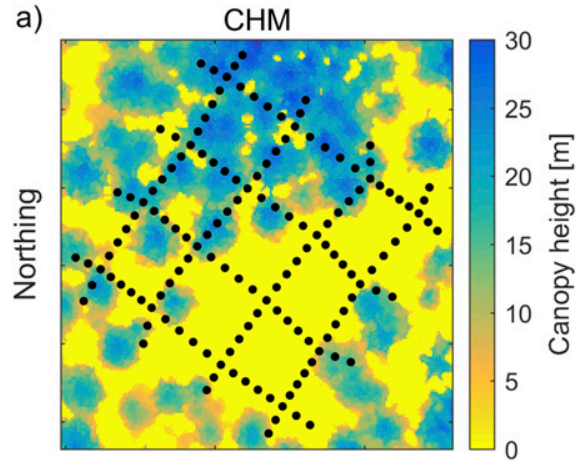

b)

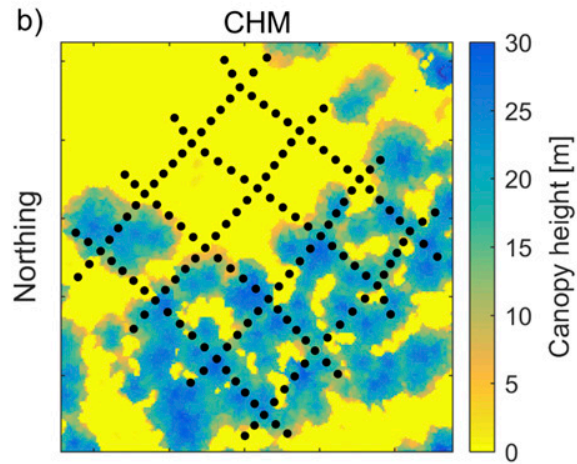

Easting
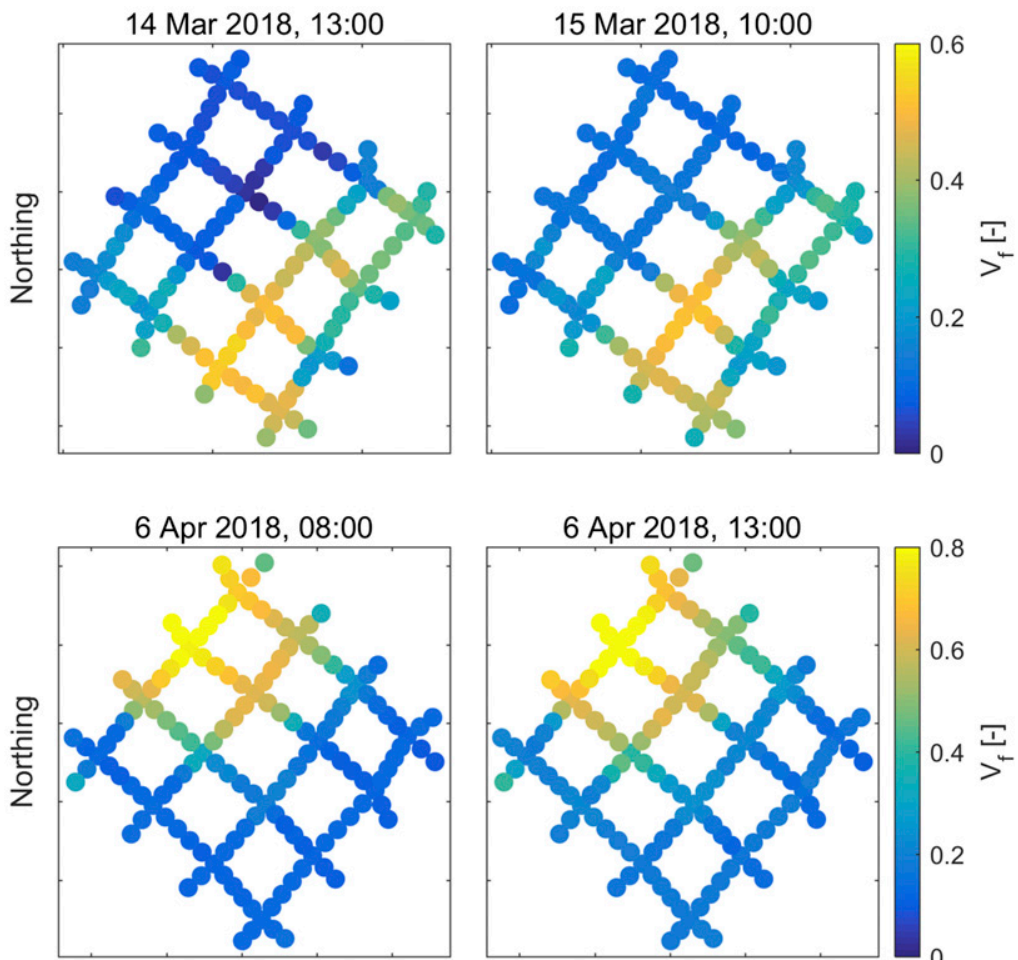

Easting

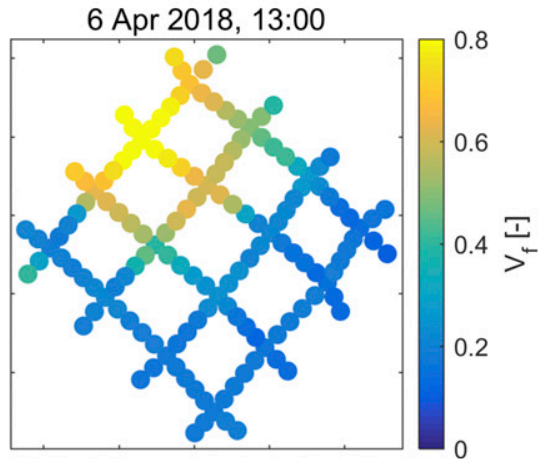

Easting

FIG. 7. (left) Canopy height map (CHM) derived from lidar data and (center),(right) corresponding sky-view fraction measurements, contrasting repeated acquisitions (a) on a clear-sky and on an overcast day, where sky-view fractions are computed based on longwave radiation data in the former case $\left(V_{f, \mathrm{LW}}\right)$ and based on shortwave radiation data in the latter $\left(V_{f, \mathrm{SW}}\right)$, and (b) on a clear-sky day at different times of the day, sky-view fraction being computed from longwave radiation measurements in both cases $\left(V_{f, \mathrm{LW}}\right.$ only). The black dots in the left panels mark the location of the grids on the CHM. 
a)

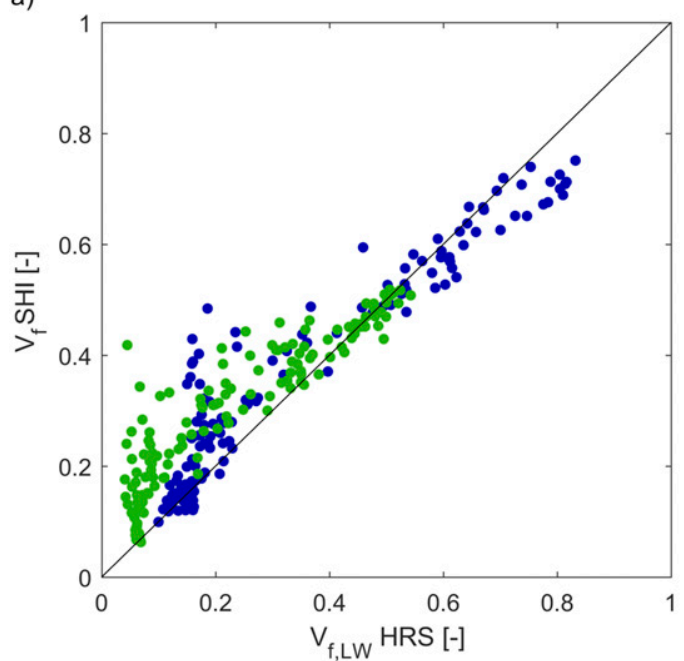

b)

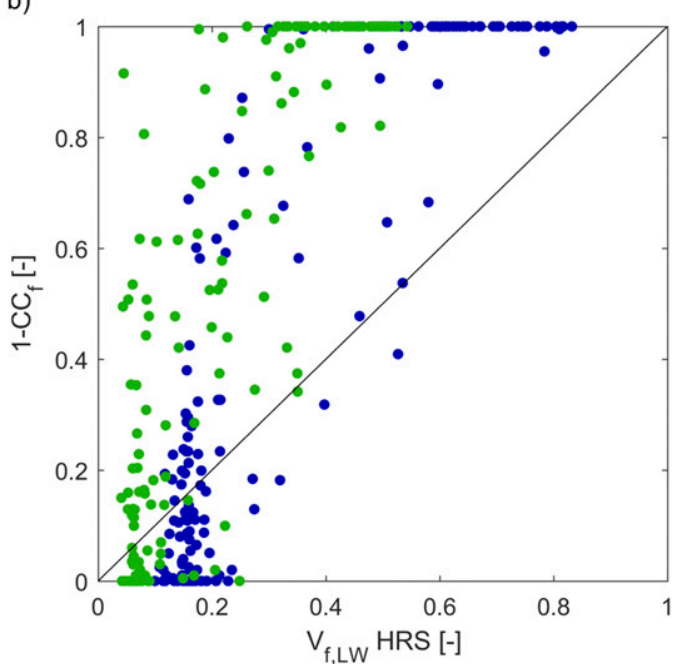

FIG. 8. Correlation between sky-view fraction computed from HRS $\left(V_{f, \mathrm{LW}}\right)$ against (a) sky-view fraction derived from corresponding synthetic hemispherical images and (b) canopy-cover fraction based on the canopy height model, for the two plots shown in Fig. 7a (blue) and Fig. 7b (green).

properties are additionally linked to apparent sky emittance as a proxy for cloudiness (cf. section 2c). These data illustrate the inverse linear relationship between longwave radiation enhancement and sky-view fraction, where longwave enhancement gradients across varying canopy structure increase as cloud cover is reduced. Consequently, dense canopies coincide with the strongest longwave enhancement, but also experience the largest variability depending on meteorological conditions. In contrast, cloud cover has a quasi-binary effect on local shortwave transmissivity. The good correspondence of transmissivity and sky-view fraction typical of overcast conditions is opposed to an apparent bimodal distribution of local transmissivity values in the absence of clouds. The entire range of transmissivity values is covered in the former case, but transmissivity varies between very high $(>0.8)$ or very low $(<0.3)$ values in the latter, with rare occurrence of intermediate values. Here, it is mainly controlled by the occurrence of direct insolation or canopy shading at a given survey time.

\section{Discussion}

\section{a. HRS as a tool to characterize canopy structure}

To our knowledge, this is the first setup to deploy both a pyrgeometer and a pyranometer combined in a portable assembly for spatially distributed in situ measurements. This assembly enables two complementary methods to derive sky-view fraction based on long- or shortwave radiation data, which adds flexibility with regards to meteorological conditions, but also offers the opportunity to cross-validate $V_{f}$ data by independent methods. Consistent sky-view fraction estimates from repeated radiometer surveys (section 3a, Figs. 3a and 4), their excellent agreement with values derived from HP (section 3b, Figs. 6a,b), and robust spatial sky-view fraction patterns (Fig. 7) demonstrate a very good performance of the HRS at a similar accuracy to the HP method (Figs. 6c,d), but with more extensive spatial coverage. A standard HRS campaign including eight plots, installation, and clearance of the instrumentation, can be conducted within a day. At the walking speed suggested for high-resolution surveys, continuous $V_{f}$ measurements can be discretized to independent values at 2-m resolution given the settling time of the sensors $(<20 \mathrm{~s})$, resulting in $8 \times 144 V_{f}$ values per campaign. Subsequent data processing does not include subjective steps in the workflow and involves minimal computational requirements and data volume. Acquiring the same amount of data using traditional HP would require about 12 days, conservatively assuming a time demand of 5 min for each HP acquisition, supervised thresholding and subsequent $V_{f}$ calculation. Furthermore, our results confirm that $V_{f}$ estimates from HP depend on meteorological conditions, entail substantial processing effort (Seidel et al. 2011; Jonckheere et al. 2004), and may be compromised by subjective decisions (Jonckheere et al. 2005; Pueschel et al. 2012).

While the comparison to lidar-based canopy parameters served primarily as application example, it demonstrates that the hemispherical perspective of an upward-looking sensor, characteristic for sky-view fraction and highly relevant to radiative transfer (Figs. 9-11; e.g., Sicart et al. 2004), 

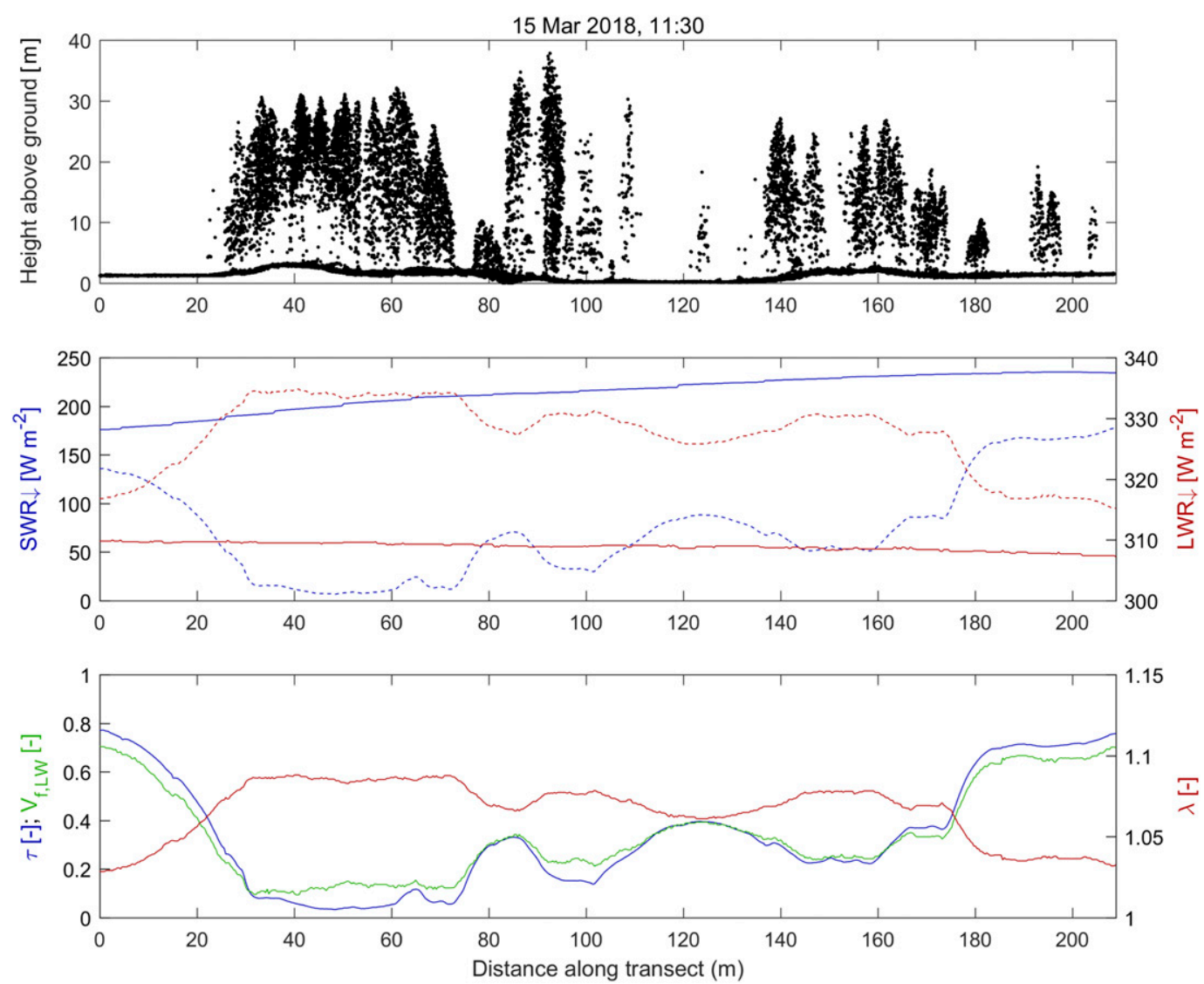

FIG. 9. HRS transect in Laret under overcast conditions, including (a) transects through the heightnormalized lidar point cloud (buffer: $5 \mathrm{~m}$ ) in the upper panel; (b) measured radiation data in the central panel (continuous lines: open-site reference measurements; dashed lines: measurements within forest); (c) corresponding longwave radiation enhancement, shortwave radiation transmissivity and sky-view fraction data $\left(V_{f, \mathrm{LW}}\right)$ in the lower panel.

is difficult to approximate by vertically projected datasets (Fig. 8). Information acquired from downward-looking sensors cannot fully replace in situ measurements, and even approaches that apply coordinate conversion to mimic the in situ sensor view point currently fail to capture the entire range of sky-view fraction seen by the HRS. Here, HRS could provide validation data over wide spatial extents, supporting further improvement of methodologies to extract sky-view fraction from data acquired by airborne platforms [e.g., as those presented by Reid et al. (2014a), Varhola and Coops (2013), and Moeser et al. (2014)]. HRS data could further be used to determine transfer functions to derive sky-view fraction proxies from more widely available remote sensing products such as aerial imagery and canopy height models (e.g., Essery et al. 2008b; Ginzler and Hobi 2015).

Transect measurements cannot provide full 2D coverage, yet they reveal distinct spatial patterns that would be substantially harder to capture with single point measurements. As such, continuous sky-view fraction data retrieved from HRS are valuable for exploring methods to upscale canopy properties from very high (e.g., $1 \mathrm{~m}$ ) to coarser spatial resolutions (e.g., $100 \mathrm{~m}$ ). Land surface models commonly parameterize canopy by area-averaged properties (Best et al. 2011; Bonan et al. 2018; Boone et al. 2017), failing to account for any structural heterogeneity at the subgrid level, with possible implications for model transferability and performance (Essery et al. 2009; Broxton et al. 2015). Coupling distributions of sky-view fraction and, for instance, forest snow, could enhance our understanding of canopy structure controls on snow accumulation and ablation processes at both distributed and spatially aggregated scales (e.g., Veatch et al. 2009; Moeser et al. 2015).

\section{b. HRS as a tool to inform spatially distributed canopy radiative transfer models}

Subcanopy irradiance, in particular shortwave radiation, varies considerably over short distances (Rowlands et al. 2002; Musselman et al. 2012). Consequently, stationary 

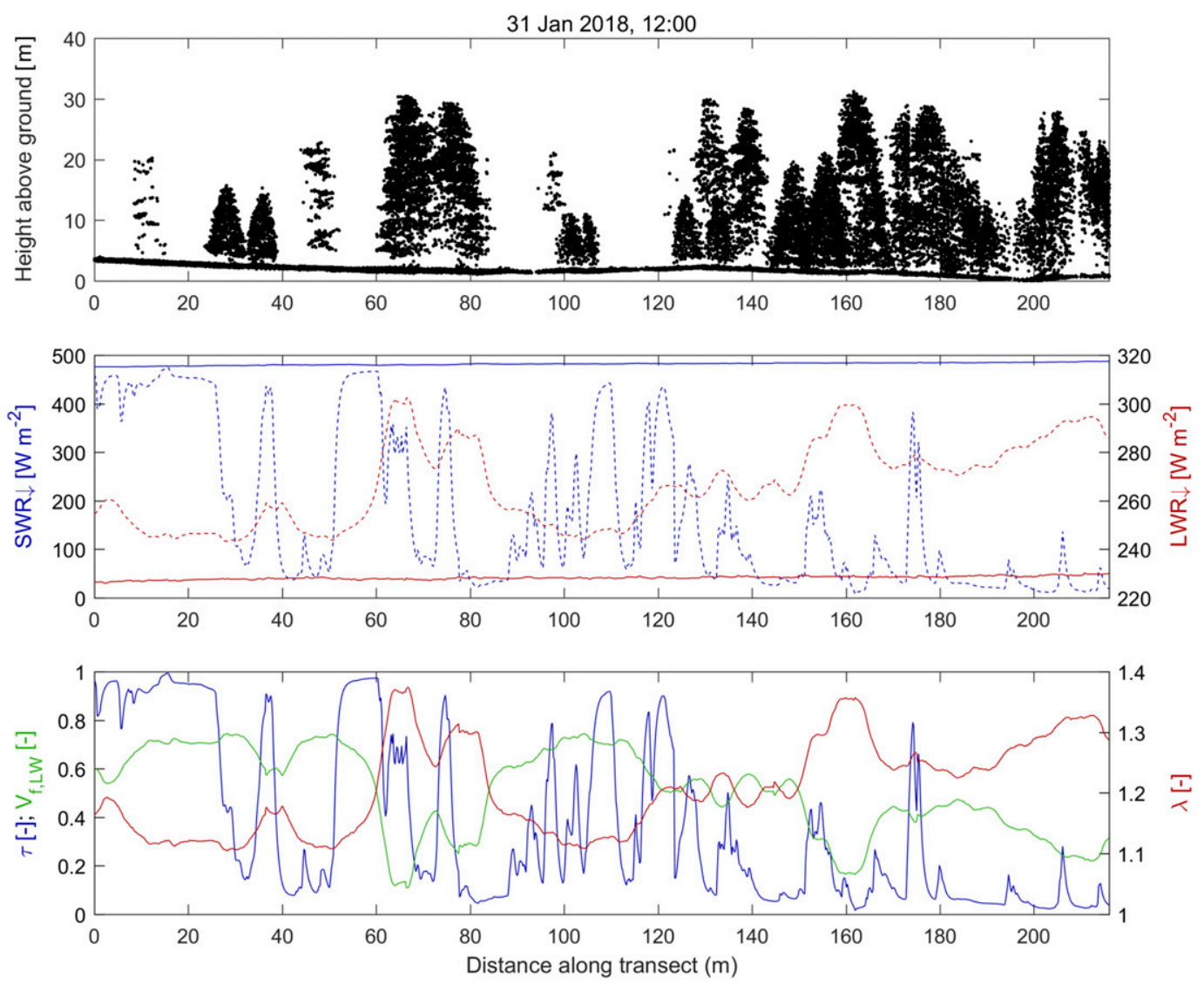

FIG. 10. As in Fig. 9, but for an HRS transect in Flin under clear-sky conditions.

sensor arrays deployed to capture site-representative spatial averages of subcanopy irradiance (Link et al. 2004; Webster et al. 2016b), within-site variability (Hardy et al. 2004; Pomeroy et al. 2008), and the combined influences of canopy structure and meteorological conditions (Sicart et al. 2004; Reid et al. 2014b; Rowlands et al. 2002; Essery et al. 2008a) have typically included at least 10 pyranometers and 3 pyrgeometers (Webster et al. 2016b). Experimental studies specifically designed to address irradiance variability in canopy discontinuities (Lawler and Link 2011; Musselman et al. 2015) have even used up to 30 sensors. The trade-off between sensor costs, measurement resolution and spatial extent limits the capabilities of stationary sensor arrays to survey spatial scales representative of watershed and land surface model grid cells $(>100 \mathrm{~m} \times 100 \mathrm{~m})$. While moving fixed installations on rail or cable systems (Chen et al. 1997; Stähli et al. 2009; Webster et al. 2016a) can only partially overcome these limitations, the handheld radiometer is specifically designed to compensate for these shortcomings. The portable setup allows extensive spatial coverage, while minimizing instrument costs (two sensors only). Although HRS cannot replace stationary sensors, the combination of HRS and stationary setups can provide valuable and complementary spatially and temporally resolved data.

Existing radiative transfer models as presented by Seyednasrollah et al. (2013), Webster et al. (2017), Musselman et al. (2015), and Essery et al. (2008b) were developed based on time series from stationary sensors, but rely on spatially limited experimental data. HRS can fill this gap by offering validation data across a variety of canopy structures and meteorological conditions, the example in section $3 \mathrm{~d}$ showing how HRS data from different sites and acquisition dates can be combined to capture these superimposed effects. Our observations corroborate findings of previous studies based on stationary sensor arrays, revealing maximum longwave radiation enhancement in denser forest surroundings and clear-sky conditions (e.g., Sicart et al. 2004; Pomeroy et al. 2009; Webster et al. 2017; Klos and Link 2018). The results further confirm that variations in shortwave radiation transmissivity are mainly controlled by relative contributions of diffuse and direct components (Hardy et al. 2004; Pomeroy and Dion 1996; Sicart et al. 2004), without apparent influence of canopy properties. 
a)

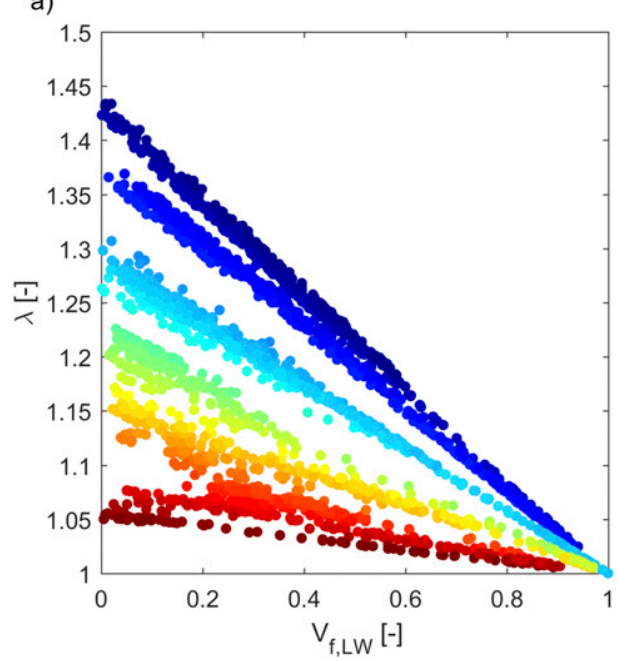

b)

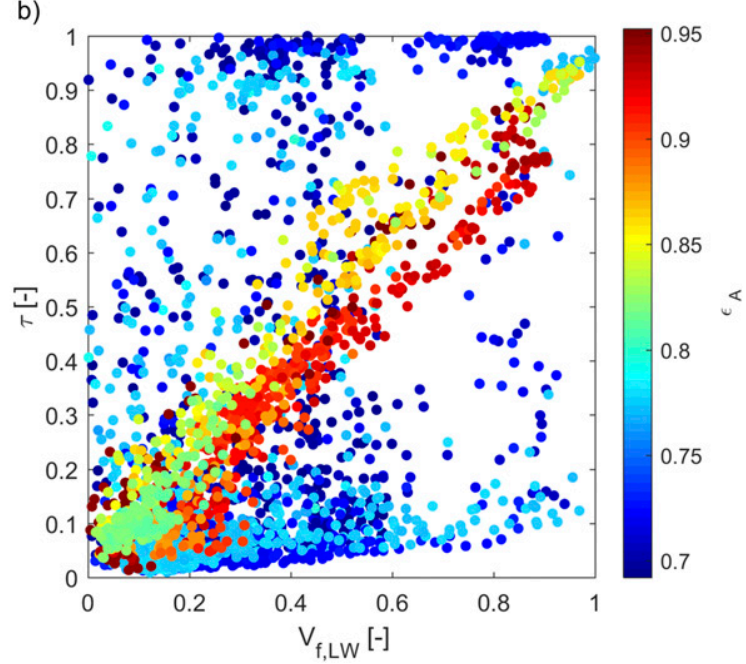

FIG. 11. Data from 20 plots demonstrating the combined effects of sky-view fraction ( $V_{f, \mathrm{Lw}} ; x$ axis $)$ and cloud cover (color scale: apparent sky emittance) on (a) longwave radiation enhancement and (b) shortwave radiation transmissivity ( $y$ axis).

As for sky-view fractions, HRS-based irradiance datasets are suitable to assess both subgrid variability as well as spatial averages at scales typical of land surface model grid cells and thus support model upscaling efforts. In particular, HRS could be applied to study the spatially integrated irradiance on grid cells that include both homogeneous closed forest as well as discontinuities such as edges and larger forest gaps, where Broxton et al. (2015) found the largest mismatches between finescale and coarse-resolution models. For spatially integrated measurements, HRS can be conducted at a much faster pace (e.g., at $1 \mathrm{~m} \mathrm{~s}^{-1}$ ). In situ measurements of canopy transmissivity and longwave enhancement at this spatial scale have not been attempted before, but they address the research gap highlighted, for example, by Lawler and Link (2011), Reid et al. (2014b), and Musselman et al. (2015).

\section{c. Influences of meteorological conditions and implications for future surveys}

Despite the assets of HRS, varying performance for contrasting meteorological conditions (section 3a) illustrates the consequences of violating the underlying assumptions. Our results suggest that HRS applications should consider the following factors:

1) Offset between atmospheric and canopy longwave radiation: Differences between longwave radiation components from sky and canopy determine the sensitivity of sky-view fraction to incoming subcanopy longwave radiation $\left(d V_{f} / \mathrm{LW}_{\downarrow \mathrm{FS}}\right.$; Essery et al. 2008a; Sicart et al. 2004). Clear-sky conditions therefore allow for optimal resolution of sky-view fraction using longwave radiation data $\left(V_{f, \mathrm{LW}}\right)$. Under overcast conditions, similar atmospheric and canopy longwave emittance hamper accurate sky-view fraction estimates from longwave radiation, but canopy transmissivity for shortwave radiation captures patterns in sky-view fraction equally well $\left(V_{f, \mathrm{sw}}\right.$; Pomeroy et al. 2009).

2) Offset between canopy and air temperature: Estimates of $V_{f, \mathrm{LW}}$ can be compromised by biases associated with using open-site air temperature as a proxy for effective canopy temperature. This assumption requires differences between air temperatures in the forest and in the open to be negligible (i.e., $T_{a \mathrm{OS}}=$ $\left.T_{a \mathrm{FS}}\right)$ and thermal equilibrium of the canopy with the surrounding air (i.e., $T_{\text {can }}=T_{a \mathrm{FS}}$ ). While this is sufficiently accurate when solar radiation input is low (Sicart et al. 2004; Webster et al. 2017), it may not apply on clear-sky days and at high solar elevation angles (Lawler and Link 2011; Pomeroy et al. 2009), with opposing effects on sky-view fraction calculations depending on forest characteristics and insolation. In dense forests where little shortwave radiation penetrates the canopy, below-canopy air temperatures may be lower than those seen at adjacent open areas. Resulting overestimation of $V_{f}$ observed in Fig. 5 (blue curve) confirms that forest can act as a cold sink, an effect described, for example, by Link and Marks (1999) and Webster et al. (2016a). In contrast, in sparse forests at high solar angles a substantial part of the canopy is exposed to solar radiation. In this situation, below-canopy air temperatures have been 
reported to exceed air temperatures measured at adjacent open areas (Pomeroy et al. 2009; Webster et al. 2017), which can explain an underestimation of $V_{f}$ (cf. mismatch between repeated $V_{f}$ measurements in Fig. 3b). Consequently, air temperature measurements within the forest should be a better predictor of canopy temperatures. However, when vertical gradients in canopy temperatures exist, a single belowcanopy air temperature measurement may not fully represent effective canopy temperatures. Here, preferential heating of the upper canopy (Webster et al. 2017) can cause an underestimation of sky-view fraction (Fig. 5, green curve).

3) Error sources not related to meteorology: The spatial offsets between our open sites and the surveyed forest plots were small compared to other studies (e.g., Musselman et al. 2015). However, in the presence of a partial cloud cover, the reference measurement may no longer be representative of above-canopy conditions due to the temporal mismatch in the cloud masking between the open and the forest site. Further, snow interception in the canopy can severely hamper application of HRS. With snow in the canopy, canopy temperatures can be considerably offset from air temperatures, and measurements can be compromised by canopy snow unloading. Finally, potential errors arising from a simplified treatment of terrain influence should be considered. Assuming an open site air temperature measurement to represent the average surface temperature of the surrounding terrain may be inadequate in some settings, for example, in steep and/or nonforested terrain. However, any discrepancy between these two temperatures is typically minor compared to their difference to the radiative sky temperature, while $V_{f}$ is high by definition (open site). Hence estimating $\mathrm{LW}_{\text {sky }}$ based on Eq. (2.5) should provide fairly accurate estimates.

In summary, when HRS are applied to determine skyview fraction, we recommend that they occur on clear-sky days during morning hours using the longwave radiation data. Alternatively, we advise to conduct HRS in the presence of a homogeneous cloud cover, in which case the shortwave radiation data should be used. HRS should generally be avoided when cloud cover is variable and rapidly changing, and in the presence of canopy snow. In contrast, HRS aimed at studying radiation transfer dynamics can be carried out under almost all conditions. For shortwave transmissivity [Eq. (2.2)], twilight hours should be avoided due to different timing of local sunset and sunrise at the open and the forested sites. Fast moving variable cloud cover may require some temporal averaging of the radiation data, depending on the distance between the two sites. For longwave enhancement [Eq. (2.1)] ensuring that the open site yields accurate estimates of $\mathrm{LW}_{\text {sky }}$ based on Eq. (2.5) is the only requirement.

\section{Conclusions}

This study presented a novel, portable handheld radiometer setup developed for surveys along forest transects. When coupled to reference measurements at nearby open sites, data acquired with the setup can be used to retrieve spatially continuous estimates of skyview fraction $V_{f}$, canopy transmissivity $\tau$, and longwave enhancement $\lambda$. We could demonstrate that handheld radiometer surveys (HRS) provide an efficient method to derive a widely used canopy structure parameter and allow in situ characterization of subcanopy irradiance regimes over large spatial extents that cannot be covered by other in situ methods (i.e., HP and stationary sensors). The approach was tested at several forest sites encompassing a variety of canopy structures as well as for different meteorological conditions. In clear skies prior to intensive insolation of the canopy, longwave radiation data from HRS yielded sky-view fraction at an accuracy similar to hemispherical photography, while being considerably more efficient. The same was achieved in overcast conditions, deriving sky-view fraction from shortwave radiation data. Consistency between repeated acquisitions and validation against $V_{f}$ data from hemispherical images (RMSE $\approx 0.03$ in all cases) demonstrates a very good performance of the method, which, however, deteriorated in the presence of a partial cloud cover or when strong daytime warming compromised the thermal equilibrium between canopy and air. Furthermore, spatially continuous measurements of canopy transmissivity and longwave enhancement along discontinuous forest transects provide a new level of insight into the links between spatial variability of subcanopy irradiance and the overhead canopy structure. HRS therefore perfectly complement commonly used stationary sensor arrays, which remain indispensable to capture the temporal variability of irradiance. The application of HRS for generating spatially distributed datasets of both canopy structure and subcanopy irradiance make it a useful tool to support process model upscaling efforts. Here, HRS data can enable the development and testing of enhanced radiative transfer schemes that explicitly account for structural heterogeneity of forest canopies, and help to bridge the gap between observed small-scale variability and coarseresolution model simulations.

Acknowledgments. This project was funded by the Swiss National Science Foundation (SNF, project 
169213). We thank Elena Stautzebach and Luca Iacolettig for assistance in the field and support with analysis of hemispherical images. We would further like to thank Clare Webster for her help with lidar data processing and for many constructive discussions related to this work, and Chris Hoyle for reviewing the English of this paper. The effort of two anonymous reviewers, whose comments have improved the quality of this article, is gratefully acknowledged.

\section{REFERENCES}

Battaglia, M. A., P. Mou, B. Palik, and R. J. Mitchell, 2002: The effect of spatially variable overstory on the understory light environment of an open-canopied longleaf pine forest. Can. J. For. Res., 32, 1984-1991, https://doi.org/10.1139/x02-087.

Beckschäfer, P., D. Seidel, C. Kleinn, and J. Xu, 2013: On the exposure of hemispherical photographs in forests. iForest Biogeosci. For., 6, 228-237, https://doi.org/10.3832/ ifor0957-006.

Best, M. J., and Coauthors, 2011: The Joint UK Land Environment Simulator (JULES), model description - Part 1: Energy and water fluxes. Geosci. Model Dev., 4, 677-699, https://doi.org/ 10.5194/gmd-4-677-2011.

Bogren, W. S., J. F. Burkhart, and A. Kylling, 2016: Tilt error in cryospheric surface radiation measurements at high latitudes: A model study. Cryosphere, 10, 613-622, https://doi.org/10.5194/ tc-10-613-2016.

Bonan, G. B., E. G. Patton, I. N. Harman, K. W. Oleson, J. J. Finnigan, Y. Lu, and E. A. Burakowski, 2018: Modeling canopy-induced turbulence in the Earth system: A unified parameterization of turbulent exchange within plant canopies and the roughness sublayer (CLM-ml v0). Geosci. Model Dev., 11, 1467-1496, https://doi.org/10.5194/gmd-111467-2018.

Boone, A., P. Samuelsson, S. Gollvik, A. Napoly, L. Jarlan, E. Brun, and B. Decharme, 2017: The interactions between soil-biosphere-atmosphere land surface model with a multienergy balance (ISBA-MEB) option in SURFEXv8 - Part 1: Model description. Geosci. Model Dev., 10, 843-872, https:// doi.org/10.5194/gmd-10-843-2017.

Broxton, P. D., A. A. Harpold, J. A. Biederman, P. A. Troch, N. P. Molotch, and P. D. Brooks, 2015: Quantifying the effects of vegetation structure on snow accumulation and ablation in mixed-conifer forests. Ecohydrology, 8, 1073-1094, https:// doi.org/10.1002/eco.1565.

Chen, J. M., P. D. Blanken, T. A. Black, M. Guilbeault, and S. Chen, 1997: Radiation regime and canopy architecture in a boreal aspen forest. Agric. For. Meteor., 86, 107-125, https:// doi.org/10.1016/S0168-1923(96)02402-1.

Essery, R., J. Pomeroy, C. Ellis, and T. Link, 2008a: Modelling longwave radiation to snow beneath forest canopies using hemispherical photography or linear regression. Hydrol. Processes, 22, 2788-2800, https://doi.org/10.1002/hyp.6930.

—_, and Coauthors, 2008b: Radiative transfer modeling of a coniferous canopy characterized by airborne remote sensing. J. Hydrometeor., 9, 228-241, https://doi.org/10.1175/ 2007JHM870.1.

-, and Coauthors, 2009: SNOWMIP2: An evaluation of forest snow process simulations. Bull. Amer. Meteor. Soc., 90, 11201135, https://doi.org/10.1175/2009BAMS2629.1.
Friesen, J., J. Lundquist, and J. T. Van Stan, 2015: Evolution of forest precipitation water storage measurement methods. Hydrol. Processes, 29, 2504-2520, https://doi.org/10.1002/hyp.10376.

Ginzler, C., and M. Hobi, 2015: Countrywide stereo-image matching for updating digital surface models in the framework of the Swiss national forest inventory. Remote Sens., 7, 4343-4370, https://doi.org/10.3390/rs70404343.

Glatthorn, J., and P. Beckschafer, 2014: Standardizing the protocol for hemispherical photographs: accuracy assessment of binarization algorithms. PLOS ONE, 9, e111924, https://doi.org/ 10.1371/journal.pone.0111924.

Gray, A. N., T. A. Spies, and M. J. Easter, 2002: Microclimatic and soil moisture responses to gap formation in coastal Douglas-fir forests. Can. J. For. Res., 32, 332-343, https://doi.org/10.1139/x01-200.

Hancock, S., R. Essery, T. Reid, J. Carle, R. Baxter, N. Rutter, and B. Huntley, 2014: Characterising forest gap fraction with terrestrial lidar and photography: An examination of relative limitations. Agric. For. Meteor., 189-190, 105-114, https:// doi.org/10.1016/j.agrformet.2014.01.012.

Hardy, J. P., R. Melloh, G. Koenig, D. Marks, A. Winstral, J. W. Pomeroy, and T. Link, 2004: Solar radiation transmission through conifer canopies. Agric. For. Meteor., 126, 257-270, https://doi.org/10.1016/j.agrformet.2004.06.012.

Ishida, M., 2004: Automatic thresholding for digital hemispherical photography. Can. J. For. Res., 34, 2208-2216, https://doi.org/ 10.1139/x04-103.

Jonckheere, I., S. Fleck, K. Nackaerts, B. Muys, P. Coppin, M. Weiss, and F. Baret, 2004: Review of methods for in situ leaf area index determination. Agric. For. Meteor., 121, 19-35, https://doi.org/10.1016/j.agrformet.2003.08.027.

_ K. Nackaerts, B. Muys, and P. Coppin, 2005: Assessment of automatic gap fraction estimation of forests from digital hemispherical photography. Agric. For. Meteor., 132, 96-114, https://doi.org/10.1016/j.agrformet.2005.06.003.

Jupp, D. L., D. S. Culvenor, J. L. Lovell, G. J. Newnham, A. H. Strahler, and C. E. Woodcock, 2009: Estimating forest LAI profiles and structural parameters using a ground-based laser called 'Echidna'. Tree Physiol., 29, 171-181, https://doi.org/ 10.1093/treephys/tpn022.

Khosravipour, A., A. K. Skidmore, M. Isenburg, T. Wang, and Y. A. Hussin, 2014: Generating pit-free canopy height models from airborne lidar. Photogramm. Eng. Remote Sensing, 80, 863-872, https://doi.org/10.14358/PERS.80.9.863.

Klos, P. Z., and T. E. Link, 2018: Quantifying shortwave and longwave radiation inputs to headwater streams under differing canopy structures. For. Ecol. Manage., 407, 116-124, https://doi.org/10.1016/j.foreco.2017.10.046.

Lawler, R. R., and T. E. Link, 2011: Quantification of incoming allwave radiation in discontinuous forest canopies with application to snowmelt prediction. Hydrol. Processes, 25, 3322-3331, https://doi.org/10.1002/hyp.8150.

Link, T. E., and D. Marks, 1999: Point simulation of seasonal snow cover dynamics beneath boreal forest canopies. J. Geophys. Res., 104, $27841-27857$, https://doi.org/10.1029/ 1998JD200121.

— - — , and J. P. Hardy, 2004: A deterministic method to characterize canopy radiative transfer properties. Hydrol. Processes, 18, 3583-3594, https://doi.org/10.1002/hyp.5793.

Lundquist, J. D., S. E. Dickerson-Lange, J. A. Lutz, and N. C. Cristea, 2013: Lower forest density enhances snow retention in regions with warmer winters: A global framework developed from plot-scale observations and modeling. Water Resour. Res., 49, 6356-6370, https://doi.org/10.1002/wrcr.20504. 
Mahat, V., and D. G. Tarboton, 2012: Canopy radiation transmission for an energy balance snowmelt model. Water Resour. Res., 48, W01534, https://doi.org/10.1029/2011WR010438.

Marty, C., and R. Philipona, 2000: The clear-sky index to separate clear-sky from cloudy-sky situations in climate research. Geophys. Res. Lett., 27, 2649-2652, https://doi.org/10.1029/ 2000 GL011743.

Moeser, D., J. Roubinek, P. Schleppi, F. Morsdorf, and T. Jonas, 2014: Canopy closure, LAI and radiation transfer from airborne LiDAR synthetic images. Agric. For. Meteor., 197, 158-168, https://doi.org/10.1016/j.agrformet.2014.06.008.

—, M. Stähli, and T. Jonas, 2015: Improved snow interception modelling using canopy parameters derived from airborne LiDAR data. Water Resour. Res., 51, 5041-5059, https:// doi.org/10.1002/2014WR016724.

Musselman, K. N., N. P. Molotch, S. A. Margulis, P. B. Kirchner, and R. C. Bales, 2012: Influence of canopy structure and direct beam solar irradiance on snowmelt rates in a mixed conifer forest. Agric. For. Meteor., 161, 46-56, https://doi.org/10.1016/ j.agrformet.2012.03.011.

— J. W. Pomeroy, and T. E. Link, 2015: Variability in shortwave irradiance caused by forest gaps: Measurements, modelling, and implications for snow energetics. Agric. For. Meteor., 207, 69-82, https://doi.org/10.1016/j.agrformet.2015.03.014.

Nobis, M., and U. Hunziker, 2005: Automatic thresholding for hemispherical canopy-photographs based on edge detection. Agric. For. Meteor., 128, 243-250, https://doi.org/ 10.1016/j.agrformet.2004.10.002.

Otsu, N., 1979: A threshold selection method from grey-level histograms. IEEE Trans. Syst. Man Cybern., 9, 62-66, https:// doi.org/10.1109/TSMC.1979.4310076.

Pomeroy, J. W., and K. Dion, 1996: Winter radiation extinction and reflection in a boreal pine canopy: Measurements and modelling. Hydrol. Processes, 10, 1591-1608, https://doi.org/10.1002/(SICI) 1099-1085(199612)10:12<1591::AID-HYP503>3.0.CO;2-8.

_ C. Ellis, A. Rowlands, R. Essery, J. Hardy, T. Link, D. Marks, and J. E. Sicart, 2008: Spatial variability of shortwave irradiance for snowmelt in forests. J. Hydrometeor., 9, 1482-1490, https://doi.org/10.1175/2008JHM867.1.

—, D. Marks, T. Link, C. Ellis, J. Hardy, A. Rowlands, and R. Granger, 2009: The impact of coniferous forest temperature on incoming longwave radiation to melting snow. Hydrol. Processes, 23, 2513-2525, https://doi.org/10.1002/hyp.7325.

Pueschel, P., H. Buddenbaum, and J. Hill, 2012: An efficient approach to standardizing the processing of hemispherical images for the estimation of forest structural attributes. Agric. For. Meteor., 160, 1-13, https://doi.org/10.1016/j.agrformet.2012.02.007.

Reid, T. D., and Coauthors, 2014a: Spatial quantification of leafless canopy structure in a boreal birch forest. Agric. For. Meteor., 188, 1-12, https://doi.org/10.1016/j.agrformet.2013.12.005.

__ R. L. H. Essery, N. Rutter, and M. King, 2014b: Data-driven modelling of shortwave radiation transfer to snow through boreal birch and conifer canopies. Hydrol. Processes, 28, 2987-3007, https://doi.org/10.1002/hyp.9849.

Rowlands, A., J. Pomeroy, J. Hardy, D. Marks, K. Elder, and R. Melloh, 2002: Small-scale spatial variability of radiant energy for snowmelt in a mid-latitude sub-alpine forest. Proc. 59th
Eastern Snow Conference, Stowe, VT, Eastern Snow Conference, 109-117, https:/www.usask.ca/hydrology/papers/ Rowlands_et_al_2002.pdf.

Seidel, D., S. Fleck, C. Leuschner, and T. Hammett, 2011: Review of ground-based methods to measure the distribution of biomass in forest canopies. Ann. For. Sci., 68, 225-244, https:// doi.org/10.1007/s13595-011-0040-z.

,-- , and -2012 : Analyzing forest canopies with groundbased laser scanning: A comparison with hemispherical photography. Agric. For. Meteor., 154-155, 1-8, https://doi.org/ 10.1016/j.agrformet.2011.10.006.

Seyednasrollah, B., M. Kumar, and T. Link, 2013: On the role of vegetation density on net snow cover radiation at the forest floor. J. Geophys. Res. Atmos., 118, 8359-8374, https://doi.org/ 10.1002/jgrd.50575.

Sicart, J. E., R. L. Essery, J. W. Pomeroy, J. Hardy, T. Link, and D. Marks, 2004: Sensitivity study of daytime net radiation during snowmelt to forest canopy and atmospheric conditions. J. Hydrometeor., 5, 774-784, https://doi.org/10.1175/ 1525-7541(2004)005<0774:ASSODN >2.0.CO;2.

Song, G.-Z. M., D. Doley, D. Yates, K.-J. Chao, and C.-F. Hsieh, 2014: Improving accuracy of canopy hemispherical photography by a constant threshold value derived from an unobscured overcast sky. Can. J. For. Res., 44, 17-27, https:// doi.org/10.1139/cjfr-2013-0082.

Stähli, M., T. Jonas, and D. Gustafsson, 2009: The role of snow interception in winter-time radiation processes of a coniferous sub-alpine forest. Hydrol. Processes, 23, 2498-2512, https:// doi.org/10.1002/hyp.7180.

Varhola, A., and N. C. Coops, 2013: Estimation of watershed-level distributed forest structure metrics relevant to hydrologic modeling using LiDAR and Landsat. J. Hydrol., 487, 70-86, https://doi.org/10.1016/j.jhydrol.2013.02.032.

— G. W. Frazer, P. Teti, and N. C. Coops, 2012: Estimation of forest structure metrics relevant to hydrologic modelling using coordinate transformation of airborne laser scanning data. Hydrol. Earth Syst. Sci., 16, 3749-3766, https://doi.org/10.5194/hess-16-3749-2012.

Veatch, W., P. D. Brooks, J. R. Gustafson, and N. P. Molotch, 2009: Quantifying the effects of forest canopy cover on net snow accumulation at a continental, mid-latitude site. Ecohydrology, 2, 115-128, https://doi.org/10.1002/eco.45.

Webster, C., N. Rutter, F. Zahner, and T. Jonas, 2016a: Modeling subcanopy incoming longwave radiation to seasonal snow using air and tree trunk temperatures. J. Geophys. Res. Atmos., 121, 1220-1235, https://doi.org/10.1002/2015JD024099.

$\ldots,-,-$, and $-2016 \mathrm{~b}$ : Measurement of incoming radiation below forest canopies: A comparison of different radiometer configurations. J. Hydrometeor., 17, 853-864, https:// doi.org/10.1175/JHM-D-15-0125.1.

$\longrightarrow,-$ - and T. Jonas, 2017: Improving representation of canopy temperatures for modeling subcanopy incoming longwave radiation to the snow surface. J. Geophys. Res. Atmos., 122, 9154-9172, https://doi.org/10.1002/2017JD026581.

Zhang, Y., J. M. Chen, and J. R. Miller, 2005: Determining digital hemispherical photograph exposure for leaf area index estimation. Agric. For. Meteor., 133, 166-181, https://doi.org/ 10.1016/j.agrformet.2005.09.009. 